\title{
ROCHAS VULCÂNICAS ALCALINAS DA FORMAÇÃO QUIXABA DE FERNANDO DE NORONHA, PE: QUÍMICA MINERAL E LITOGEOQUÍMICA
}

\author{
ROSANA PEPORINE LOPES ${ }^{1} \&$ MABEL NORMA COSTAS ULBRICH ${ }^{2}$
}

\begin{abstract}
ALKALINE VOLCANIC ROCKS FROM FERNANDO DE NORONHA QUIXABA FORMATION: MINERAL AND ROCK CHEMISTRY The lava flows of the Quixaba Formation $(4,2-1,5 \mathrm{Ma})$ are olivine melanephelinites (OLM), olivine melilite melanephelinites (MEM) and pyroxene melanephelinites (PIM), with levels of pyroclastic rocks and relatively thin basanite flows (BAS). Thick BAS sequences occur in Baia do Sancho and in the São José, Cuscuz and de Fora islets. Olivine compositions $(\mathrm{m \#}=85-75)$ in melanephelinites and most BAS match those of clinopyroxenes (mg\# $=86-74)$, indicating equilibrium crystallization. The São José and Cuscuz basantitic olivine (mg\# 72-70) and clinopyroxene (mg\# = 79-74) compositions are similar and denote more differentiated rocks.

In MEM, the amount ( $>10 \%$ to $<2 \%$ ) and composition of melilites are variable. The melilite-rich rocks have abundant olivine, with melilites poorer in $\mathrm{MgO}$ and richer in $\mathrm{Al}_{2} \mathrm{O}_{3}$. $\mathrm{Ba}$, Ti- (and $\mathrm{F}$ ) rich phlogopite and biotite are late minerals with typical chemical features in each rock type. The $\mathrm{SiO}_{2}$ content is an indicator of the chemical differences between melanephelinites: -MEM: $37-$ 39 wt.\%; OLM: 38-40 wt.\%; PIM: 40-43 wt.\%-. BAS have 45-46 wt.\% $\mathrm{SiO}_{2}$. The increase in silica is accompanied by increase in $\mathrm{Al}_{2} \mathrm{O}_{3}$ and decrease in $\mathrm{MgO}, \mathrm{TiO}_{2}, \mathrm{Fe}_{2} \mathrm{O}_{3}, \mathrm{CaO}, \mathrm{MnO}, \mathrm{Cs}, \mathrm{Y}$ and REE. Trace element ratios show important discrepancies among the melanephelinite types: MEM O OLM: $\mathrm{La} / \mathrm{Nb}=0.6-0.7 ; \mathrm{Zr} / \mathrm{Nb}=2.7-3.2 ; \mathrm{PIM}: \mathrm{La} / \mathrm{Nb}=0.7-1.0 ; \mathrm{Zr} / \mathrm{Nb}=2.6-5.7$. The amount of trace elements and the incompatible element ratios are variable in BAS. The data presented in this paper denote the existence of crystal fractionation processes, for instance between PIM and the thin BAS flows in the lava sequence. On the other hand, the high amount of incompatible elements in the melanephelinites and the differences in element ratios in the several rock types, point to an origin from distinct parental magmas, derived from either different mantle sources, or different degrees of partial melting of the same source.
\end{abstract}

Keywords: melanephelinite; basanite; mineral chemistry; Fernando de Noronha

\begin{abstract}
Resumo A Formação Quixaba (4,2 - 1,5 Ma) é composta por derrames de vários tipos de melanefelinitos: olivina melanefelinitos (OLM), olivina melilita melanefelinitos (MEM) e piroxênio melanefelinitos (PIM), com níveis de rochas piroclásticas e estreitos derrames de basanitos (BAS). Espessas seqüências de BAS ocorrem na Baía do Sancho e formam as ilhotas de São José, Cuscuz e de Fora. As olivinas (mg\# = 85-75) e os clinopiroxênios $(m g \#=86-74)$ nos melanefelinitos e na maioria dos BAS são equiparáveis, indicando cristalização em equilíbrio. Nos BAS de São José e Cuscuz, a olivina (mg\# 72-70) e o clinopiroxênio

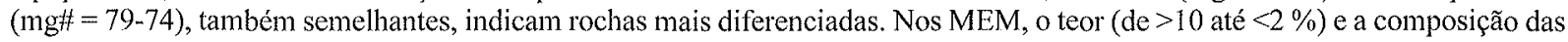
melilitas são variáveis. As rochas ricas em melilita têm abundante olivina; nesses casos as melilitas são mais pobres em $\mathrm{MgO}$ e mais ricas em $\mathrm{Al}_{2} \mathrm{O}_{3}$. Flogopita e biotita, ricas em Ba, Ti (e F), são minerais tardios, com feiçôes químicas próprias em cada tipo litológico. O teor de $\mathrm{SiO}_{2}$ (\% em peso) é um indicador das diferenças químicas entre os melanefelinitos -MEM: 37-39\%; OLM: 38-40\%; PIM: 40-43\%- Os BAS possuem 45-46\% de $\mathrm{SiO}_{2}$. $\mathrm{O}$ aumento de sílica é acompanhado por aumento de $\mathrm{Al}_{2} \mathrm{O}_{3}$ e decréscimo de $\mathrm{MgO}, \mathrm{TiO}_{2}, \mathrm{Fe}_{2} \mathrm{O}_{3 \text { total }}, \mathrm{CaO}, \mathrm{MnO}, \mathrm{Cs}, \mathrm{Y}$ e REE. Nos nefelinitos, as razões entre elementos traços mostram diferenças significativas: MEM e OLM: La/ $\mathrm{Nb}=0,6-0,7 ; \mathrm{Zr} / \mathrm{Nb}=2,7-3,2 ; \mathrm{PIM}: \mathrm{La} / \mathrm{Nb}=0,7-1,0 ; \mathrm{Zr} / \mathrm{Nb}=2,6-5,7$ (Ulbrich et al. 2004). Entre os basanitos, tanto o teor de alguns elementos traços como as razões entre elementos incompatíveis mostram-se variáveis. Os dados apresentados neste trabalho indicam que há evidências de processos de cristalização fracionada, por exemplo, entre os PIM e os basanitos que formam níveis relativamente estreitos na seqüência de derrames. Entretanto, o elevado teor de elementos incompatíveis dos melanefelinitos e as diferenças entre as razões desses elementos nos vários tipos litológicos apontam para uma origem a partir de magmas parentais distintos, originados em fontes mantélicas distintas, ou por diferentes graus de fusão da mesma fonte.
\end{abstract}

Palavras-chaves: melanefelinito, basanito, química mineral, Fernando de Noronha

INTRODUÇÃO Nefelinitos e melanefelinitos, com ou sem melilita, juntamente com melilititos, subordinados, são rochas com ampla distribuição geográfica, aparecendo em regiões continentais e em ilhas oceânicas (Brey 1978, Alibert et al. 1983, Le Bas 1987, Hoernle \& Schmincke 1993). Em ambos ambientes ocorrem normalmente associados a basanitos e álcali-basaltos mostrando, nos continentes, estreita relação com kimberlitos e carbonatitos (Moore \& Verwoerd 1985). O estudo dos melanefelinitos desperta interesse uma vez que a composição química dos mesmos, em particular daqueles portadores de melilita, que apresentem elevados teores de $\mathrm{MgO}$, poderiam ter a composição de magmas primários (Brey 1978).

No Arquipélago de Fernando de Noronha foram gerados extensos derrames de melanefelinitos, dentre os quais alguns portadores de melilita, bem como esparsos derrames de basanitos, durante o episódio vulcânico mais recente, o da Formação Quixaba. O escopo deste trabalho é apresentar e discutir as variações petrológicas deste conjunto de rochas, com base nos trabalhos de campo, na petrográfia e na química dos minerais e das rochas.

Geologia da área $\mathrm{O}$ Arquipélago de Fernando de Noronha, situado a $345 \mathrm{~km}$ da costa brasileira, na latitude $3^{\circ} 53^{\prime}-3^{\circ} 48^{\prime} \mathrm{S}$ e longitude $32^{\circ} 28^{\prime}-32^{\circ} 23^{\prime} \mathrm{W}$, é constituído por uma ilha principal, rodeada por 20 ilhotas e rochedos (Fig. 1). Essas ilhas, com área total em torno de $19 \mathrm{~km}^{2}$ constituem o cume de um edifício vulcânico cuja base repouśa a $4.000 \mathrm{~m}$ de profundidade e constituem a parte oriental da Cadeia de Fernando de Noronha. As 


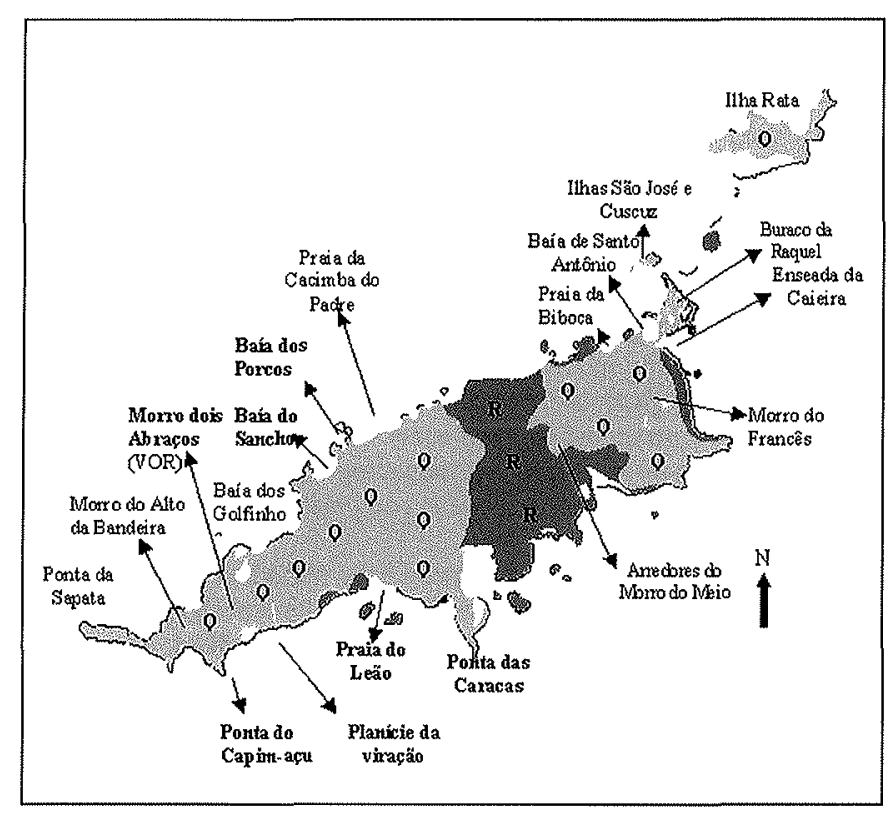

Figura 1 - Mapa simplificado do arquipélago de Fernando de Noronha mostrando as regiões de ocorrência das rochas das formações: Remédios (cinza escuro-R) e Quixaba (Q). Em negrito estão destacados os locais onde foram realizados perfis esquemáticos dos derrames da Formação Quixaba.

elevações submersas da Cadeia de Fernando de Noronha, de direção ENE-WSW, parecem ter continuação no continente, com as manifestações magmáticas alcalinas do distrito de Fortaleza, Ceará (Almeida 1983, Almeida et al. 1988) e com os álcali-basaltos do Rio Grande do Norte (Fodor et al. 1998).

No Arquipélago de Fernando de Noronha, Almeida (1955) reconheceu duas formações geológicas de rochas vulcânicas alcalinas, separadas por um evento erosivo, denominando-as de Remédios e Quixaba. Datações posteriores indicam idades de 12,3 a 8 Ma para a Formação Remédios e de 4,2 a 1,5 Ma para a de Quixaba (Cordani 1970, Cordani et al. 2003).

A Formação Remédios compreende uma unidade basal de rochas piroclásticas - brechas, tufos e aglomerados- exposta na ilha principal, cortada por corpos de fonólito, traquito, traquiandesito, álcali-basalto, essexito e uma grande variedade de diques ultrabásicos, básicos e de lamprófiros (Almeida 1955, Ulbrich et al. 2004).

As maiores intrusões desta formação são os domos fonolíticos, comumente atravessados por diques máficos. Outros corpos de contorno elíptico ou subcircular que se destacam na paisagem são um sill de essexito na Praia do Atalaia, cortado por diques de lamprófíros alcalinos, de traquiandesito e de fonólito, além dos domos traquíticos da Praia do Leão e da Praia da Biboca, os pequenos plugs de traquiandesito da Baía do Sueste e o plug de álcali-basalto da Enseada do Abreu, atravessado por diques de traquiandesito.

Após um período de erosão que destruiu completamente os aparelhos vulcânicos externos da Formação Remédios, expondo as rochas hipoabissais, houve novas manifestações vulcânicas, que geraram as rochas da Formação Quixaba (Almeida 1955). $\mathrm{Na}$ parte oriental da ilha principal destaca-se uma chaminé, o Morro do Francês (com $210 \mathrm{~m}$ de altura) com lava e escória de composição melanefelinítica. Algumas chaminés pequenas, localizadas perto do nível do mar, na Baía de Santo António, são identificadas pela presença de estruturas subcirculares, marcadas pela disposição periférica de escória e brechas fortemente alteradas, com distinta coloração ferrugem ou lilás, e núcleos ocupados por rochas melanefeliníticas de conduto. Os diques são raros nesta formação. Identificaram-se alguns diques de melanefelinito, cortando rochas piroclásticas da Formação Remédios, além de escassos corpos de nefelinito e melilita melanefelinito, intrusivos nos derrames da Formação Quixaba.

As rochas vulcânicas predominantes são melanefelinitos (denominados ankaratritos por Almeida 1955). Os derrames, com espessuras que variam desde alguns centímetros até poucos metros, estão comumente intercalados com rochas piroclásticas da mesma composição e com escassos niveis de basanito. Uma amostra de melabasanito (ankaramito, Ulbrich et al. 2004) foi obtida na base de um dos Morros Dois Irmãos. Os basanitos estão expostos no corte vertical da Baía do Sancho (Ulbrich \& Ruberti 1992) e na Planície da Viração (Lopes 2002), além daqueles já descritos por Almeida (1955), nas ilhas São José, Cuscuz e de Fora.

$\mathrm{Na}$ Baía do Sancho, os espessos pacotes subhorizontais de basanitos (com aproximadamente $50 \mathrm{~m}$ ) atravessam os melanefelinitos e as rochas piroclásticas. Já os derrames isolados que compõem as ilhotas de São José, Cuscuz e de Fora, carregam abundantes xenólitos do manto (dunitos, espinélio lherzolitos, etc., Rivalenti et al. 2000; Kogarko et al. 2001). Para Almeida (1955) essas rochas constituem a Formação São José, que estaria colocada em discordância por sobre os derrames de melanefelinitos da Formação Quixaba. Por outro lado para Ulbrich \& Ruberti (1992), a existência de basanitos em meio às rochas ultramáficas sugere que a atividade magmática do evento Quixaba gerou tanto manifestações de melanefelinitos como de basanitos, e que as rochas da Ilha São José poderiam ser contemporâneas ou mais jovens, formando, porém, parte do mesmo evento efusivo.

CLASSIFICAÇÃO E NOMENCLATURA Ulbrich (1993) separou as rochas ultrabásicas e ultramáficas da Formação Quixaba em dois grupos petrográficos: melanefelinitos do tipo $\mathrm{A}$ (com fenocristais de olivina), e do tipo B (com fenocristais de olivina e clinopiroxênio).

Estudos mais recentes (Lopes \& Ulbrich 2001, Lopes 2002) discutem novamente a classificação e nomenclatura das rochas da Formação Quixaba, com base na classificação mineralógica modal (Le Maître 1989) acompanhada da classificação química normativa proposta por Le Bas (1989) que separa as rochas segundo a porcentagem de nefelina e albita normativas. Os melanefelinitos de Fernando de Noronha são assim divididos em três tipos principais: olivina melanefelinitos (OLM), piroxênio melanefelinitos (PIM) e olivina melilita melanefelinitos (MEM), que incluem os olivina melanefelinitos portadores de melilita. A nomenclatura deste último grupo baseia-se na quantidade de melilita modal (Le Maître 1989). Os melabasanitos e basanitos contêm plagioclásio cálcico entre os minerais essenciais. Análises modais de rochas dos vários tipos litológicos aparecem na Tabela 1.

\section{DISTRIBUIÇÃO REGIONAL E PETROGRAFIA DAS} ROCHAS Em geral, a separação em campo dos diferentes tipos de melanefelinitos torna-se difícil por tratar-se de rochas de coloração negra a cinza bem escura, estrutura maciça a amigdaloidal e textura porfiritica de matriz afanítica, na qual se destacam apenas pequenos fenocristais de olivina (menores que $3 \mathrm{~mm}$ ), verde escura quando fresca, ou castanha quando mais alterada.

Olivina melanefelinitos (OLM) Os derrames de OLM ocorrem ao longo de toda ilha principal, com excelentes exposições, tanto na porção oriental (Enseada da Caieira, Baía de Santo Antônio, Praia da Biboca e Morro do Francês) quanto na oci- 
Tabela I - Análises modais representativas dos melanefelinitos e basanitos da Formação Quixaba. Valores expressos em porcentagem.

\begin{tabular}{|c|c|c|c|c|c|c|c|}
\hline Amostra & 99FN21b & 99FN63 & UCFN37 & 97FN31 & 97FN44b & 97FN32b & 97FN20 \\
\hline Classificação & MEM & MEM & MEM & MEM & OLM & OLM & OLM \\
\hline Nefelina & 20,2 & 22,0 & 37,0 & 32,8 & 36,2 & 0,0 & 0,0 \\
\hline Vidro & 0,0 & 0,0 & 0,0 & 0,0 & 0,0 & 33,1 & 26,0 \\
\hline Feldspato & 0,0 & 0,0 & 0,0 & 0,0 & 0,0 & 0,0 & 0,0 \\
\hline Diopsídio & 24,7 & 30,3 & 32,1 & 34,6 & 18,3 & 40,5 & 40,2 \\
\hline Opaco & 25,4 & 23,0 & 12,3 & 19,8 & 24,3 & 15,2 & 20,8 \\
\hline Olivina & 16,7 & 16,0 & 10,3 & 10,1 & 17,8 & 9,3 & 11,0 \\
\hline Melilita & 10,0 & 6,7 & 5,3 & 1,4 & 0,0 & 0,0 & 0,0 \\
\hline Apatita & 1,6 & 1,0 & 2,3 & $\mathrm{tr}$ & $\operatorname{tr}$ & $\operatorname{tr}$ & $\operatorname{tr}$ \\
\hline Mica & 1,4 & 1,0 & 0,7 & 0,6 & 1,0 & 1,5 & 1,8 \\
\hline Amígdalas & 0,0 & 0,0 & 0,0 & $\mathrm{tr}$ & 2,0 & $\operatorname{tr}$ & 0,0 \\
\hline Total & 100,0 & 100,0 & 100,0 & 100,0 & 100,0 & 100,0 & 100,0 \\
\hline Amostra & 97FN39 & 97FN46 & 97FN13d & 99FN4 & 99FN22 & 99FN9a & 99FN10b \\
\hline Classificação & PIM & PIM & PIM & BAS & BAS & BAS & BAS \\
\hline Nefelina & 0,0 & 13,2 & 0,0 & 4,6 & 0,0 & 0,0 & 0,0 \\
\hline Vidro & 17,0 & 12,2 & 24,1 & $\operatorname{tr}$ & $\mathrm{tr}$ & $\mathrm{tr}$ & 9,4 \\
\hline Feldspato* & 1,5 & 0,0 & 0,0 & 21,2 & 20,0 & 22,5 & 34,0 \\
\hline Diopsídio & 43,2 & 40,9 & 45,7 & 42,7 & 48,4 & 49,0 & 39,3 \\
\hline Opaco & 22,2 & 18,9 & 12,7 & 12,7 & 19,4 & 13,5 & 9,6 \\
\hline Olivina & 13,7 & 9,6 & 9,2 & 10,7 & 12,0 & 13,0 & 6,6 \\
\hline Melilita & 0,0 & 0,0 & 0,0 & 0,0 & 0,0 & 0,0 & 0,0 \\
\hline Apatita & $\operatorname{tr}$ & 1,6 & 4,6 & 3,2 & $\operatorname{tr}$ & 2,0 & 1,0 \\
\hline Mica & 0,9 & 2,2 & 3,3 & 4,4 & 0,0 & 0,0 & 0,0 \\
\hline Amígdalas & $\operatorname{tr}$ & 1,4 & $\operatorname{tr}$ & $\operatorname{tr}$ & 0,0 & 0,0 & $\operatorname{tr}$ \\
\hline Total & 100,0 & 100,0 & 100,0 & 100,0 & 100,0 & 100,0 & 100,0 \\
\hline
\end{tabular}

dental (Praia do Leão, Ponta das Caracas, Ponta do Capim-açu, Ponta do Barro Vermelho e Baía do Sancho - Fig. 1). Os OLM predominam também na Ilha Rata. Normalmente intercalados a estas rochas aparecem níveis piroclásticos ou derrames de PIM ou de MEM.

Ao microscópio são facilmente separáveis dos demais melanefelinitos por possuírem apenas fenocristais de olivina, às vezes acompanhados de escassos microfenocristais de clinopiroxênio.

Os fenocristais de olivina apresentam-se fraturados, isolados ou agrupados, com inclusões de minerais opacos e mais raramente de flogopita. As bordas encontram-se reabsorvidas e normalmente alteradas para cloritas e carbonatos (menos comum), em alguns casos observa-se alteração parcial ou total para iddingsita (Fig. 2). No caso específico do Morro do Francês, ao redor dos grãos de olivina desenvolveu-se uma faixa marcada por pequenos cristais de nefelina, prismas curtos de clinopiroxênio incolor e grãos opacos, configurando uma coroa de reação em função de desequilíbrio com a matriz.

As outras fases microfenocristalinas presentes são: prismas castanho-pálidos de clinopiroxênio com bordas rosadas enriquecidas em titânio $(<1,5 \mathrm{~mm})$; flogopitas ou biotitas subédricas $(<0,5 \mathrm{~mm})$ pleocróicas $(\mathrm{x}=$ castanho pálido, $\mathrm{z}=$ marrom avermelhado ou $\mathrm{x}=$ amarelo, $\mathrm{z}=$ amarelo rosado) e grãos opacos de minerais cúbicos agrupados ou isolados.

A matriz é marcada ora por micrólitos de nefelina entre os quais aparecem grãos opacos, prismas de clinopiroxênio, grãos de olivina, flogopita ou biotita, agulhas de apatita e, ocasionalmente, perovskita, ora pela ausência dos micrólitos e a presença de uma base félsica poiquilítica, de nefelina ou analcima, que inclui os demais minerais.

Olivina melilita melanefelinitos e olivina melanefelintos portadores de melilita (MEM) Os MEM são os tipos mais escassos. Em meio ao arquipélago foram identificados alguns poucos derrames $(0,5$ a $3 \mathrm{~m}$ de espessura) e um único dique, já em avançado grau de alteração. Os da Ponta da Sapata, do Morro Dois Abraços, da Ilha Rata e da região da Planície da Viração são descobertas inéditas (Lopes 2002), enquanto que os amostrados na região de Capim-Açú (am. 99FN56a) e na Praia do Leão (am. 97FN31) aparentam ser os mesmos citados por Almeida (1955). As rochas com melilita são mais comuns no vulcanismo da porção ocidental da Ilha Principal.

Ao microscópio, os MEM exibem textura porfirítica marcada pelos feno e microfenocristais (4 a $0,5 \mathrm{~mm}$ ) de olivina, parcialmente alterados para clorita ou carbonato. A melilita aparece como microfenocristais euedrais - de 0,2 a $0,3 \mathrm{~mm}$-, ou como componentes da matriz - grãos de $\pm 0,15 \mathrm{~mm}$ (Fig. 2). A quantidade de melilita modal varia de um derrame para o outro (de 1,5 $\%$ a $10 \%$, Tabela 1). Em geral com o aumento de melilita, há também incremento de olivina nas rochas. O estado de alteração da melilita é também variável, apresentando textura de tipo peg 
(Fig. 2) quando a alteração é incipiente, até exibir cor amarela canário de aspecto homogêneo nos indivíduos totalmente alterados. A matriz contém abundantes cristais euedrais de nefelina, entre os quais se dispõem os prismas curtos de clinopiroxênio e os grãos anedrais de titanomagnetita. Apatita e flogopita ocorrem em quantidades acessórias (Lopes e Ulbrich 2001, Lopes 2002).

Piroxênio melanefelinitos (PIM)

Os PIM podem ser defi- nidos como melanefelinitos algo mais evoluídos que os OLM, com um enriquecimento em clinopiroxênio acompanhado, em parte, de um empobrecimento em olivina e aparecimento, em alguns casos, de esparsas ripas de sanidina ou anortoclásio como constituintes da matriz (Tabela 1; am. 97FN39).

Apesar de sua ocorrência ser mais escassa do que a dos OLM, foram amostrados derrames tanto do lado oriental (Praia da Biboca, proximidades do Morro do Meio, Enseada da Caieira e Baía do Santo Antônio) quanto do lado ocidental (morros
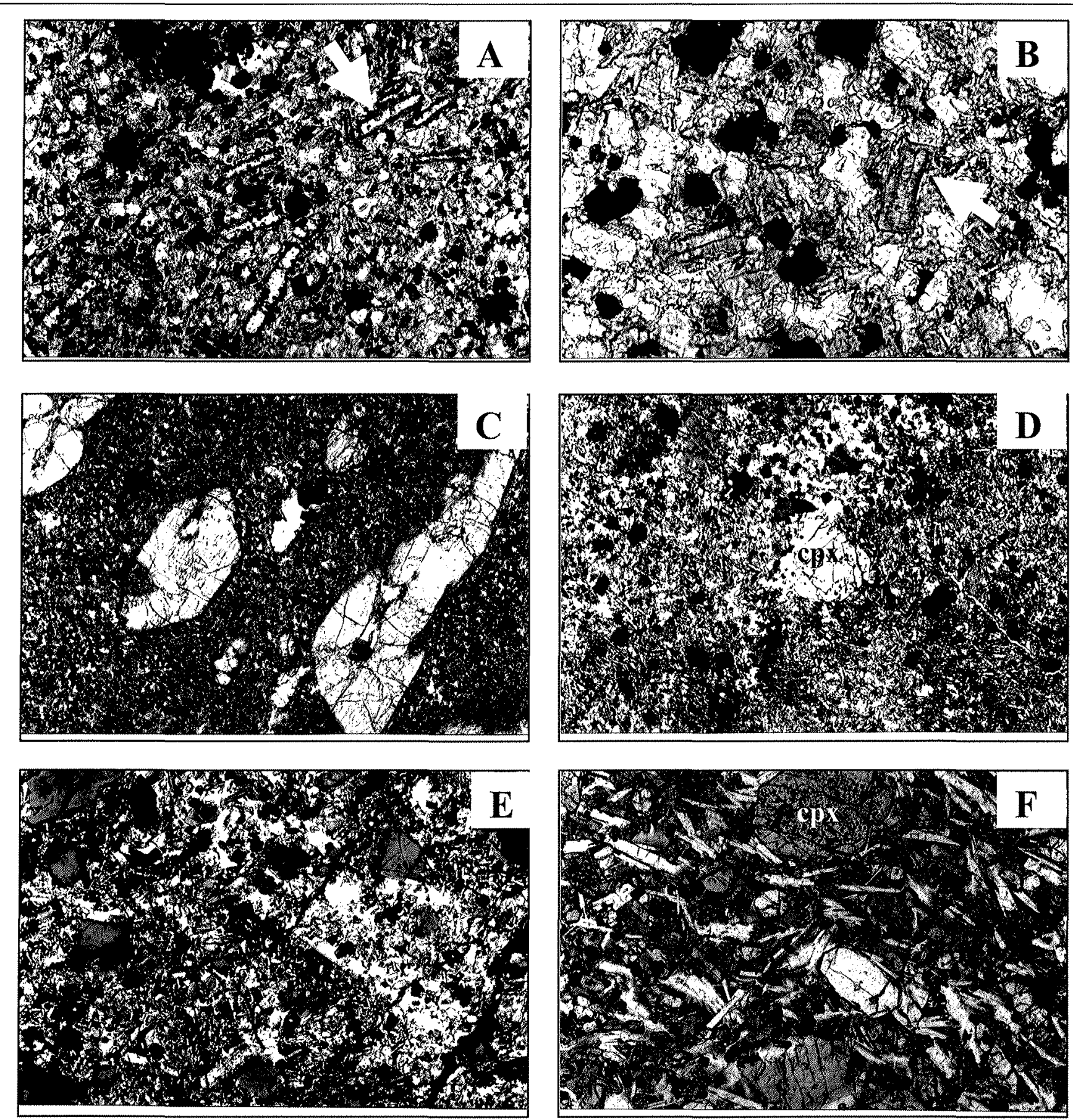

Figura 2 - Aspectos gerais dos MEM- (A e B), OLM (C), PIM (D) e BAS (E e F). A-am. 99FN63-Microfenocristais de melilita tabulares (100x). B-am.97FN31-Detalhe de melilitas alteradas, com estrutura do tipo peg (200x). C-am. $99 F N 2-F e n o c r i s t a i s ~ d e$ olivina com borda de iddingsita (50x). D- $97 F N 13 d$ - Microfenocristal reabsorvido de diopsidio (50x). E-am. 99 FN48 - matriz poiquilitica de plagioclásio englobando cristais de olivina e cpx, polarizadores cruzados (50x). F- 99FNI0b-Cristais de plagioclásio orientados - brancos - com abundante material vitreo intersticial e microfenocristal de cpx com textura alveolar (50x). 
do Alto da Bandeira e Dois Abraços, Alto da Ponta do Barro Vermelho e praias do Leão e da Cacimba do Padre) da ilha principal. Esses derrames estão posicionados, ora em níveis mais ao topo da seqüência, ora em cotas inferiores próximas ao nivel do mar, intercalados aos MEM ou OLM.

As rochas são porfiríticas a fortemente porfiríticas, com feno e microfenocristais de clinopiroxênio e de olivina em matriz muito fina, que freqüentemente exibe as mesmas fases já descritas nos OLM.

Basanitos (BAS) Os BAS representam as rochas mais evoluídas da Formação Quixaba (Ulbrich \& Ruberti 1992, Ulbrich et al. 1994).

Em campo estes basanitos distinguem-se facilmente dos melanefelinitos associados pela sua tonalidade cinza claro, ou marrom-ocre quando mais alterados. Como já observado por Ulbrich \& Ruberti (1992), na Baía do Sancho o contato com o melanefelinito é nitidamente discordante. $\mathrm{O}$ aspecto geral dos afloramentos é o de derrames de lava basanítica intercalados nas rochas ultramáficas.

Lopes (2002) tentou, a partir da realização de vários perfis verticais e horizontais, delimitar os contatos dessas rochas com os melanefelinitos encaixantes. Esses perfis mostraram que na Baía do Sancho, na altura do nível do mar, os basanitos encontram-se acima de um derrame de OLM, que se estende tanto para a Baía dos Porcos e aparentemente também para a Baía dos Golfinhos (Fig. 1). Por outro lado, na Baía dos Porcos, entre as cotas 0 a $40 \mathrm{~m}$ não são observadas rochas basaníticas, mas intercalações de derrames de OLM, rochas piroclásticas e derrames de PIM. Em cotas superiores aos 60 metros, em direção ao Morro Dois Abraços, este basanito desaparece e em seu lugar são reconhecidos derrames de PIM e MEM.

Ao microscópio, as rochas da Baía do Sancho apresentam uma textura fortemente porfiritica com feno- e microfenocristais de olivina quase totalmente substituídos por iddingsita, e de clinopiroxênio, subédrico, com fraco zoneamento concêntrico. Em alguns casos, o clinopiroxênio possui núcleos incolores corroídos e repletos de inclusões de grãos opacos e bordas bege, com fraco pleocroísmo. Além destes fenocristais são observados cristais maiores de plagioclásio tabulares $(<1,5 \mathrm{~mm})$, com apatitas inclusas. A matriz é marcada por uma base poiquilítica feldspática (Fig. 2), que rodeia os fenocristais de olivina e clinopiroxênio e inclui prismas longos e castanhos de clinopiroxênio, grãos opacos, apatita e, em algumas amostras, flogopita. Da base para o topo, há mudanças na textura das rochas, principalmente a partir das porções intermediárias, com desenvolvimento de cristais maiores e aumento no teor de minerais félsicos (Ulbrich \& Ruberti 1992, Lopes 2002).

Por outro lado, os outros níveis de basanitos intercalados com os melanefelinitos na ilha principal e os das Ilhas São José, Cuscuz e de Fora são texturalmente diferentes dos da Baía do Sancho. Possuem uma matriz muito fina com ripas de plagioclásio subparalelas entre as quais se desenvolvem os prismas de clinopiroxênio castanho-esverdeados, grãos opacos e apatita. $\mathrm{Na}$ ilha de São José, os derrames são cortados por um dique também de basanito. A rocha do dique (99FN10b) é mais pobre em olivina e apresenta matriz inequigranular onde, em alguns pontos, é possível notar o desenvolvimento de cristais maiores de plagioclásio e um aumento do teor de material vítreo totalmente fresco (Fig. 2).

QUÍMICA MINERAL Os principais minerais componentes das rochas foram analisados no Laboratório de Microssonda Eletrônica do Departamento de Mineralogia e Geotectônica (GMG) do Instituto de Geociências da Universidade de São Paulo.

Os trabalhos foram realizados num equipamento JEOL JXA
- $8600 \mathrm{~S}$, utilizando padrões internacionais, sob as seguintes condições analíticas: voltagem de aceleração de $15 \mathrm{kV}$, corrente do feixe de elétrons de $20,1 \eta \mathrm{A}$, diâmetro do feixe de $10 \mu \mathrm{m}$ para os feldspatóides ou de $5 \mu \mathrm{m}$ para os demais minerais, tempo médio de contagem de 20 seg e correções pelo software PROZA.

Olivina Os feno- e microfenocristais de olivina dos vários tipos de melanefelinitos e da maioria dos basanitos são, em geral, homogêneos e exibem valores de mg\# entre 85 e 81 em diferentes amostras (Fig. 3). Possuem entre 39 e $41 \%$ em peso de $\mathrm{SiO}_{2}$ e baixos teores de $\mathrm{NiO}(0-0,2 \%)$ e $\mathrm{CaO}$ (em torno de $0,2 \%)$. Nas bordas dos raros fenocristais que apresentam zoneamento e, principalmente, em diminutos prismas da matriz, com valores de mg\# entre 78 e 71 e com 38 a $37 \%$ de $\mathrm{SiO}_{2}$ (tabela 2 ), aumentam o $\mathrm{CaO}(0,4-0,6 \%)$ e o $\mathrm{MnO}$ (até $0,7 \%$ ).

Nos basanitos das Ilhas de São José e Cuscuz, tanto as olivinas dos fenocristais, como as da matriz, exibem composição química restrita, semelhante à da matriz dos demais basanitos (mg\# entre 72 e $70 \%$ ), 0,4\% de $\mathrm{CaO}$ e 0,4 a $0,6 \%$ de $\mathrm{MnO}$.

Clinopiroxênio Os clinopiroxênios, diopsídios com $\mathrm{Fe}^{2+} \mathrm{e}$ $\mathrm{Fe}^{3+}$, apresentam mg\# entre 74 e 86 , teores variáveis de $\mathrm{Al}_{2} \mathrm{O}_{3}$ e $\mathrm{TiO}_{2}$ e entre 0,4 e $0,6 \%$ em peso de $\mathrm{Na}_{2} \mathrm{O}$. Pequenas quantidades de $\mathrm{Cr}_{2} \mathrm{O}_{3}$ (até $0,7 \%$ ) ocorrem nos clinopiroxênios dos PIM e BAS (tabela 2, Fig. 4).

Os maiores valores de mg\# são encontrados nos diopsídios dos MEM (Fig. 4). Alguns cristais da matriz exibem mg\# entre 78 e 75 , com teores mais elevados de $\mathrm{Al}_{2} \mathrm{O}_{3}( \pm 7 \%)$ e $\mathrm{TiO}_{2}( \pm 4$ $\%$ ). Nos OLM e PIM os valores mais altos de mg\# (em torno de 83) correspondem a núcleos de fenocristais, que em alguns casos exibem zoneamento concêntrico e desenvolvimento de fina borda castanho-rosada enriquecida em titânio ( $\mathrm{TiO}_{2}$ até $7 \%$ ). Nessas bordas e também em vários prismas da matriz dos OLM e PIM, com mg\# 80-74, os teores de $\mathrm{Al}_{2} \mathrm{O}_{3}$ variam entre 7 e $12 \%$.

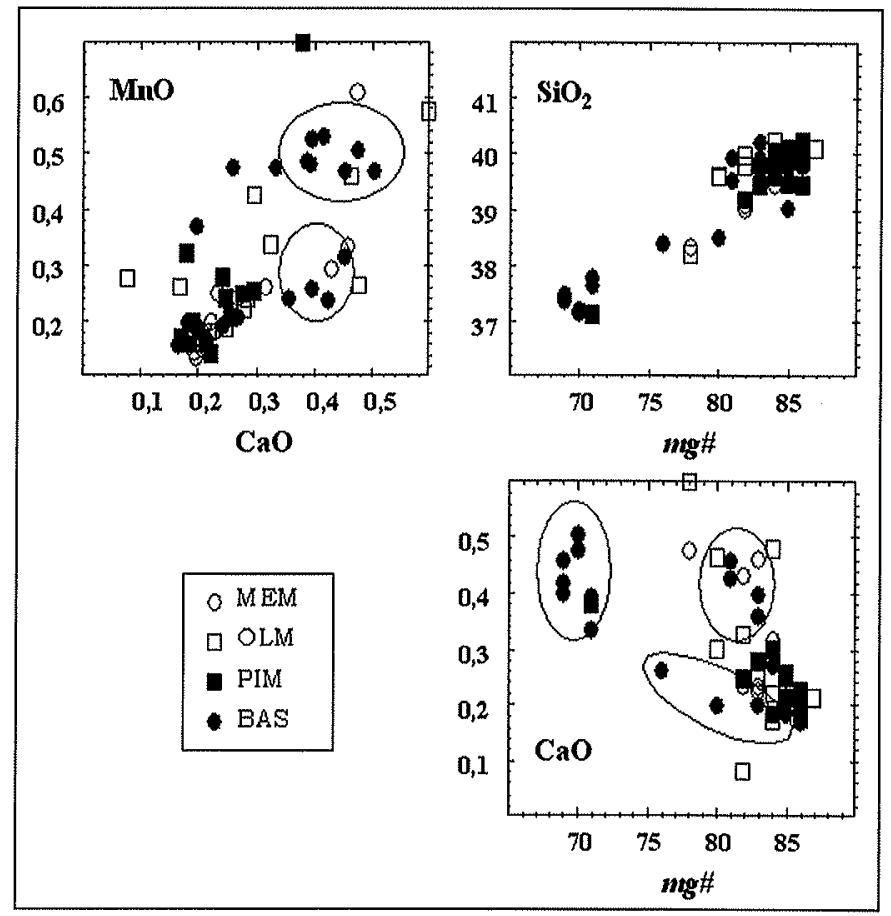

Figura 3 - Comportamento químico das olivinas dos melanefelinitos e basanitos. Óxidos em mol \%, $\mathrm{mg} \#=100^{*} \mathrm{Mg} /(\mathrm{Mg}$ $\left.+F e^{2+}\right)$. Campo $A=$ basanitos ilhas São José e Cuscuz, Campo $B=$ basanito ilha principal - Planície da Viração, am. 99FN22; Campo $C=$ basanitos ilha principal - Baia do Sancho. 
Tabela 2 - Análises químicas representativas de olivina e clinopiroxênio dos melanefelinitos e basanitos.

\begin{tabular}{|c|c|c|c|c|c|c|c|c|c|c|c|c|c|c|c|c|c|}
\hline Mineral & & & livina & & & & & Mineral & & & & & linopiroxê & ênio & & & \\
\hline Rocha & MEM & OLM & OLM & PIM & PIM & BAS & BAS & Rocha & MEM & MEM & OLM & OLM & PIM & PIM & BAS & BAS & BAS \\
\hline Amostra & UCFN379 & 97FN58a9 & 7FN58a & 99FN14 & 99FN15 & 99FN4 9 & $99 \mathrm{~F} 10 \mathrm{~b}$ & Amostra & 97FN319 & 9 FN56b & 97FN209 & $97 F N 32 b 9$ & 7FN32d 97I & $7 F N 32 \mathrm{~d} 88^{\circ}$ & 9 FN78a 9 & $99 \mathrm{FN} 10 \mathrm{a}$ & 99FN22 \\
\hline Análise & mfeno & $n c$ & $b d$ & matriz & feno & feno & mfeno & Análise & matriz & matriz & matriz & matriz & $\mathrm{nc}$ & $b d$ & feno & matriz & matriz \\
\hline $\mathrm{SiO}_{2}$ & 39,41 & 39,96 & 39,76 & 37,11 & 40,15 & 39,02 & 37,35 & $\mathrm{SiO}_{2}$ & 52,43 & 46,44 & 50,53 & 46,10 & 46,04 & 45,02 & 51,57 & 46,48 & 48,56 \\
\hline $\mathrm{TiO}_{2}$ & 0,10 & 0,00 & 0,00 & 0,02 & 0,03 & 0,02 & 0,00 & $\mathrm{TiO}_{2}$ & 1,30 & 3,41 & 1,45 & 3,83 & 3,30 & 3,78 & 0,98 & 3,01 & 2,00 \\
\hline $\mathrm{Al}_{2} \mathrm{O}_{3}$ & 0,04 & 0,03 & 0,07 & 0,04 & 0,03 & 0,02 & 0,02 & $\mathrm{Al}_{2} \mathrm{O}_{3}$ & 0,99 & 6,40 & 2,30 & 5,68 & 6,07 & 6,90 & 2,42 & 7,12 & 4,90 \\
\hline $\mathrm{FeO}$ & 15,14 & 16,65 & 16,20 & 25,99 & 13,44 & 13,67 & 26,81 & FeOtotal & 4,90 & 5,98 & 7,30 & 6,37 & 6,52 & 6,83 & 4,88 & 7,06 & 6,00 \\
\hline $\mathrm{MnO}$ & 0,24 & 0,27 & 0,34 & 0,70 & 0,16 & 0,20 & 0,53 & $\mathrm{Cr}_{2} \mathrm{O}_{3}$ & 0,00 & 0,00 & 0,00 & 0,00 & 0,00 & 0,03 & 0,44 & 0,06 & 0,70 \\
\hline $\mathrm{MgO}$ & 45,35 & 43,18 & 43,14 & 35,97 & 46,61 & 46,77 & 35,01 & $\mathrm{MnO}$ & 0,05 & 0,07 & 0,19 & 0,09 & 0,10 & 0,12 & 0,09 & 0,09 & 0,09 \\
\hline $\mathrm{CaO}$ & 0,27 & 0,08 & 0,33 & 0,38 & 0,19 & 0,18 & 0,42 & $\mathrm{MgO}$ & 15,72 & 13,42 & 14,09 & 13,61 & 13,46 & 12,56 & 16,26 & 12,35 & 14,53 \\
\hline NiO & 0,10 & 0,13 & 0,09 & 0,01 & 0,00 & 0,20 & 0,11 & $\mathrm{CaO}$ & 24,52 & 23,93 & 23,90 & 23,85 & 23,44 & 23,33 & 22,69 & 22,65 & 23,04 \\
\hline $\mathrm{Cr}_{2} \mathrm{O}_{3}$ & 0,00 & 0,04 & 0,00 & 0,00 & 0,02 & 0,03 & 0,00 & $\mathrm{Na}_{2} \mathrm{O}$ & 0,48 & 0,36 & 0,40 & 0,39 & 0,38 & 0,42 & 0,41 & 0,63 & 0,49 \\
\hline Total & 100,65 & 100,33 & 99,90 & 100,20 & 100,61 & 100,11 & 100,25 & Total & 100,39 & 100,01 & 100,14 & 99,92 & 99,31 & 99,00 & 99,73 & 99,44 & 100,31 \\
\hline
\end{tabular}

Os diopsídios dos basanitos têm composição semelhante aos das rochas ultrabásicas, a maioria dos dados possuem valores de mg\# entre 80 e 77, exceto nos núcleos mais ricos em $\mathrm{Mg}$ de alguns fenocristais. São mais pobres em $\mathrm{CaO}$ e sistematicamente mais pobres em $\mathrm{TiO}_{2}(0,9$ a 3,5\%). Nos diopsídios dos microfenocristais e da matriz dos basanitos das ilhas São José e Cuscuz os valores de mg\# variam entre 79 e 74 .

Melilita A composição química da melilita apresenta estreita relação com o seu teor modal na rocha (tabela 1, tabela 3 e Fig. 5 ). Rochas com menos de $3 \%$ de melilita (por exemplo, amostras 97FN31 e 99FN62) apresentam grãos mais ricos em $\mathrm{Al}_{2} \mathrm{O}_{3}$, $\mathrm{Na}_{2} \mathrm{O}, \mathrm{SrO}$ e $\mathrm{BaO}$ e mais pobres em $\mathrm{CaO}$ e $\mathrm{MgO}$, do que os das rochas que apresentam em torno de $10 \%$ de melilita modal (por exemplo, a amostra 99FN21b, Fig. 5 e tabela 3). Os raros cristais frescos de melilita com fraco zoneamento químico mostram que os núcleos são um pouco mais ricos em $\mathrm{SrO}$ e as bordas mais ricas em $\mathrm{CaO}, \mathrm{Al}_{2} \mathrm{O}_{3}$ e $\mathrm{Na}_{2} \mathrm{O}$. O MgO diminui e o FeO aumenta para as bordas. A maioria dos cristais apresenta apenas algumas áreas inalteradas; nas porções marginais a estrutura do tipo peg resulta, segundo Sahama (1976), de processos metassomáticos complexos que envolvem a retirada de $\mathrm{Ca}$ e $\mathrm{Mg}$ e entrada de $\mathrm{K}$, acompanhada de $\mathrm{Si}, \mathrm{Al}$ e Fe.

Os cristais de melilita estudados exibem pequena variação em termos de akermanita (60-68\%), ferro-akermanita (10-13 $\%)$, melilita sódica $(21-27 \%)$ e gehlenita $( \pm 1 \%)$, valores estes comumente encontrados em melilitas de rochas vulcânicas (Velde \& Yoder 1977).

Espinélio e ilmenita Diminutos grãos de cromo espinélio rico em alumínio e magnésio $\left(\mathrm{Cr}_{2} \mathrm{O}_{3} \pm 22 \%, \mathrm{Al}_{2} \mathrm{O}_{3} \pm 28 \%\right.$, $\mathrm{MgO} \pm 12 \%$ ) ocorrem inclusos em algumas olivinas, nas amostras. 97FN58a (OLM) e 97FN14 (PIM), tabela 3. Os membros da série ulvoespinélio-magnetita aparecem na matriz de todas as rochas e, ocasionalmente como microfenocristais. São magnetitas titaníferas, com teores variáveis de $\mathrm{TiO}_{2}(15-24 \%), \mathrm{MnO}$ $(0,3-1,2 \%)$ e $\mathrm{ZnO}(0-0,3 \%)$. Os teores de $\mathrm{MgO}$ variam entre 2 e $6,5 \%$; os mais elevados correspondem as magnetitas dos OLM. Grãos de ilmenita ocorrem inclusos nos núcleos e nas bordas de olivinas de alguns PIM.

Flogopita e biotita Flogopita (mg\# 85 a 65) e, em alguns, casos biotita (mg\# em torno de 60) ocorrem em pequenas quantidades $(<5 \%$ modal), na matriz dos distintos melanefelinitos e nos basanitos da Baía do Sancho. (Ulbrich \& Lopes 2000). A mica é um mineral tardio nessas rochas. Placas com tamanhos que variam de 0,1 a $1 \mathrm{~mm}$, apresentam-se tanto poiquilíticas,

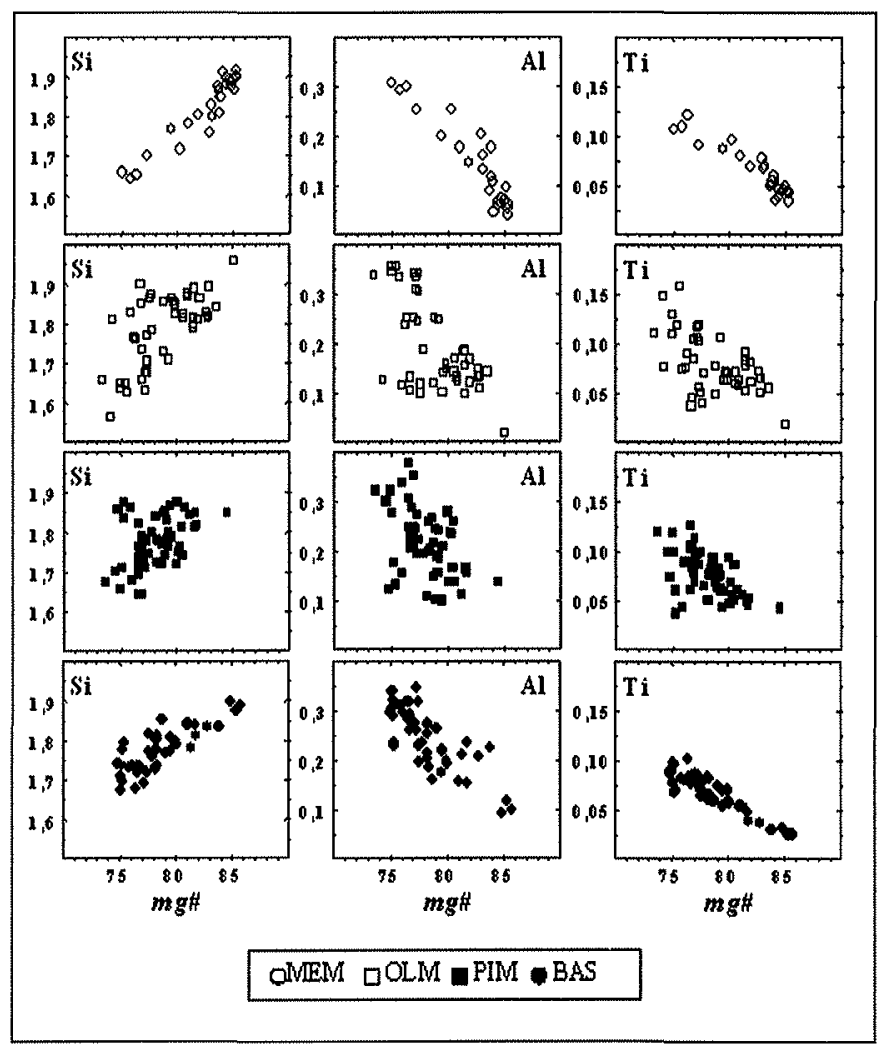

Figura 4 - Variações dos diopsidios das rochas melanefeliníticas e basaniticas. Cátions (em a.u.f.) em função do valor de $m g \#\left(100^{*} \mathrm{Mg} /\left(\mathrm{Mg}+\mathrm{Fe}^{2+}{ }_{\text {total }}\right)\right)$.

com contornos irregulares incluindo grãos opacos e agulhas de apatita, como subedrais bem desenvolvidas, projetando-se no interior de amígdalas preenchidas por zeólitas. Em algumas amostras são observados pequenos e esparsos cristais de mica bordejando fenocristais de olivina parcialmente alterados para iddingsita.

Os cristais de flogopita ricos em Ti são fortemente coloridos e pleocróicos $(\mathrm{X}=$ amarelo, $\mathrm{Y}=\mathrm{Z}=$ marrom avermelhado a marrom escuro). Os pobres em $\mathrm{Ti}$ e ricos em $\mathrm{F}$ possuem cores mais claras e pleocroísmo mais fraco ( $\mathrm{X}=$ incolor a amarelo, $\mathrm{Y}=\mathrm{Z}=$ amarelo a alaranjado). Biotitas fortemente enriquecidas em $\mathrm{BaO}\left(17\right.$ a $19 \%$ em peso) e $\mathrm{TiO}_{2}(13$ a $14 \%)$ e pobres em 
F $(<0,4 \%)$ só foram reconhecidas em uma amostra de OLM (am. 97FN58a, Fig. 6, tabela 4), mostrando-se semelhantes às que foram descritas por Mansker et al. (1979) nos nefelinitos de Oahu, Havai.

$\mathrm{O}$ elemento que melhor caracteriza as diferenças entre as micas dos quatro grupos de rochas é o $\mathrm{Ba}$ (Fig. 6). Os teores de $\mathrm{BaO}$ são menores nas micas dos $\mathrm{BAS}(\mathrm{BaO}<2 \%)$, aumentando nos $\operatorname{PIM}(\mathrm{BaO}=2$ a $9 \%)$ para alcançar maior variação e valores mais elevados nas dos OLM e MEM $(\mathrm{BaO}=3$ a $19 \%)$. Em geral, a iguais teores de $\mathrm{BaO}$, as flogopitas dos OLM e MEM tendem a ser mais ricas em $\mathrm{SiO}_{2}, \mathrm{MgO}, \mathrm{K}_{2} \mathrm{O}$ e F, e mais pobres

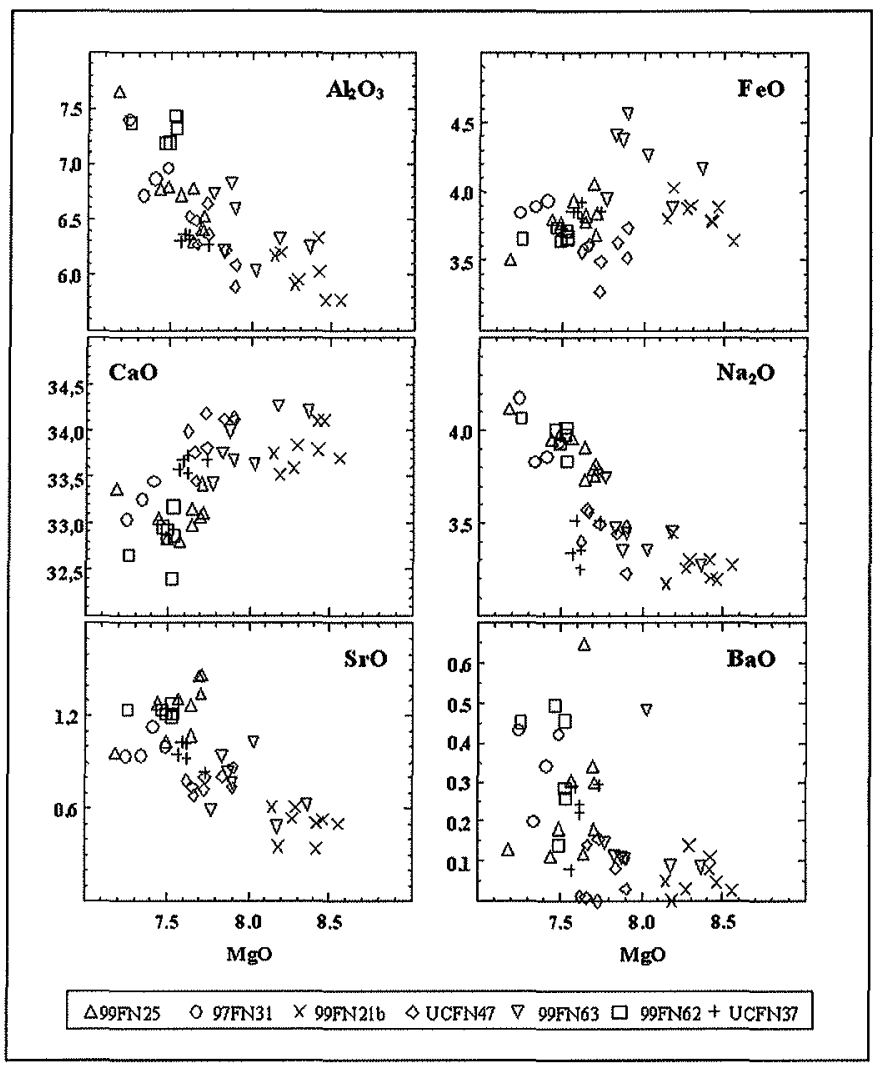

Figura 5 - Diagramas óxidos versus $\mathrm{MgO}$ (em \% em peso), mostrando as variações químicas das melilitas de sete amostras provenientes de diferentes derrames da Formação Quixaba. em $\mathrm{Al}_{2} \mathrm{O}_{3}, \mathrm{TiO}_{2}$, FeOtotal e $\mathrm{Na}_{2} \mathrm{O}$.

Em linhas gerais, com o aumento de $\mathrm{BaO}$ há diminuição sistemática de $\mathrm{SiO}_{2}$ e $\mathrm{K}_{2} \mathrm{O}$ e aumento de $\mathrm{Al}_{2} \mathrm{O}_{3}$. Observações semelhantes foram feitas por Edgar (1992) nas micas de lavas alcalinas máficas de West Eifel, Alemanha.

As micas dos OLM e MEM possuem teores de $F$ que variam entre 1,6 e $6,5 \%$, com exceção da biotita da amostra 97FN58a que tem menos de $0,6 \%$ de F. Já nos PIM e BAS o mineral apresenta quantidades mais restritas de $F(1$ a $3,8 \%)$ - tabela 4. Para os mesmos valores de F, as micas dos PIM e BAS são relativamente mais ricas em $\mathrm{SiO}_{2}$ e mais pobres em $\mathrm{Al}_{2} \mathrm{O}_{3}$. O aumento de $\mathrm{F}$ nas micas é acompanhado do aumento no teor de $\mathrm{MgO}$ e diminuição de $\mathrm{TiO}_{2}$ e $\mathrm{FeO}$.

Nefelina e feldspato A nefelina dos melanefelinitos e de uma amostra de basanito apresenta uma tendência evolutiva marcada por variações nos teores de $\mathrm{K}_{2} \mathrm{O}, \mathrm{SiO}_{2}, \mathrm{Fe}_{2} \mathrm{O}_{3}$ e $\mathrm{Na}_{2} \mathrm{O}$ (Fig. 7). Dos MEM para os OLM, PIM e BAS, ocorre queda do conteúdo de $\mathrm{K}_{2} \mathrm{O}, \mathrm{MgO}$ e $\mathrm{Fe}_{2} \mathrm{O}_{3}$ e aumento de $\mathrm{SiO}_{2}$ e $\mathrm{Na}_{2} \mathrm{O}$. Teores de SrO entre 0,1 e $0,3 \%$ em peso são encontrados unicamente nas nefelinas dos OLM.

Os feldspatos (Fig. 8) são minerais essenciais nos BAS. Na matriz de alguns PIM reconheceram-se pequenas quantidades de ripas finas de sanidina e anortoclásio enriquecidos em $\mathrm{SrO}$ (até $1,4 \%$ ) e, principalmente, em $\mathrm{BaO}(1,5$ a $5 \%$ ). Os BAS da ilha principal (por exemplo, Baía do Sancho) exibem também ripas de sanidina, acompanhando o plagioclásio dos microfenocristais e da matriz, que varia de labradorita para andesina e oligoclásio-anortoclásio. Os teores de $\mathrm{SrO}$ e $\mathrm{BaO}$ são em geral baixos, raramente encontram-se ripas de anortoclásio com até $2 \%$ desses óxidos. O feldspato alcalino está ausente nas rochas das ilhas São José e Cuscuz; o plagioclásio dos fenocristais e da matriz desses basanitos, também relativamente pobre em $\mathrm{SrO}$ e $\mathrm{BaO}$, varia de labradorita para andesina e oligoclásio.

GEOQUÍMICA DAS ROCHAS Análises químicas de elementos maiores, menores e traços, de 18 amostras dos vários tipos de rochas foram realizadas no ACTLABS, Canadá por ICP-MS

Os melanefelintos da Formação Quixaba possuem entre $37 \mathrm{e}$ $43 \%$ de $\mathrm{SiO}_{2}$ (MEM 37-39 \%; OLM 38-40\%; PIM 40-43\%) e os BAS entre 45 e $46 \%$. Os OLM e MEM mostram composição química semelhante, com algumas particularidades inerentes a uma ou outra amostra (Fig. 9, tabela 5).

Dos melanefelinitos para os basanitos há uma tendência ao

Tabela 3 - Análises químicas representativas de melilita, espinélio e ilmenita dos melanefelinitos e basanitos.

\begin{tabular}{|c|c|c|c|c|c|c|c|c|c|c|c|c|c|c|c|c|}
\hline \multirow{2}{*}{$\begin{array}{l}\text { Mineral } \\
\text { Rocha }\end{array}$} & \multirow[b]{2}{*}{ MEM } & \multicolumn{3}{|c|}{ melilita } & \multirow{2}{*}{$\begin{array}{r}\text { Mineral } \\
\text { Rocha }\end{array}$} & \multirow[b]{2}{*}{ MEM } & \multirow[b]{2}{*}{ MEM } & \multicolumn{3}{|c|}{ Espinélio } & \multirow[b]{2}{*}{ PIM } & \multirow[b]{2}{*}{ BAS } & \multirow[b]{2}{*}{ BAS } & \multirow{2}{*}{$\begin{array}{r}\text { Mineral } \\
\text { Rocha }\end{array}$} & \multicolumn{2}{|c|}{ IImenita } \\
\hline & & MEM & MEM & MEM & & & & OLM & OLM & PIM & & & & & PIM & BAS \\
\hline $\begin{array}{c}\text { Amostra } \\
\text { Análise }\end{array}$ & $\begin{array}{r}97 \mathrm{FN} 31 \\
\text { mfeno }\end{array}$ & $\begin{array}{r}\text { 99FN21b } \\
\text { matriz }\end{array}$ & $\begin{array}{r}99 F \mathrm{~F} 62 \\
\text { mfeno }\end{array}$ & $\begin{array}{r}\text { 99FN63 } \\
\text { mfeno }\end{array}$ & $\begin{array}{l}\text { Amostra } \\
\text { Análise }\end{array}$ & $\begin{array}{r}97 F N 31 \\
\text { matriz }\end{array}$ & $\begin{array}{r}97 F N 31 \\
\text { incl ol }\end{array}$ & $\begin{array}{r}97 F N 58 a \\
\text { matriz }\end{array}$ & $\begin{array}{l}\text { 97FN58a } \\
\text { incl ol }\end{array}$ & $\begin{array}{c}\text { 97FN13d } \\
\text { mfeno }\end{array}$ & $\begin{array}{r}99 \mathrm{FN} 14 \\
\text { incl ol }\end{array}$ & $\begin{array}{r}\text { 89FN78a } \\
\text { matriz }\end{array}$ & $\begin{array}{r}99 \text { FN22 } \\
\text { matriz }\end{array}$ & $\begin{array}{l}\text { Amostra } \\
\text { Análise }\end{array}$ & $\begin{array}{r}97 F N 8 \\
\text { bd ol }\end{array}$ & $\begin{array}{r}\text { 9FN78a } \\
\text { mfeno }\end{array}$ \\
\hline $\mathrm{SIO}_{2}$ & 42,99 & 42,98 & 42,61 & 43,03 & $\mathrm{TiO}_{2}$ & 19,32 & 16,80 & 18,20 & 2,79 & 23,25 & 2,09 & 17,76 & 24,59 & $\mathrm{TiO}_{2}$ & 50,34 & 48,85 \\
\hline $\mathrm{TiO}_{2}$ & 0,18 & 0,16 & 0,16 & 0,19 & $\mathrm{Al}_{2} \mathrm{O}_{3}$ & 0,82 & 1,01 & 2,42 & 27,59 & 0,57 & 30,17 & 2,06 & 1,74 & $\mathrm{Al}_{2} \mathrm{O}_{3}$ & 0,07 & 0,06 \\
\hline $\mathrm{Al}_{2} \mathrm{O}_{3}$ & 6,86 & 5,77 & 7,37 & 6,60 & $\mathrm{Cr}_{2} \mathrm{O}_{3}$ & 0,19 & 5,49 & 1,30 & 22,94 & 0,41 & 21,26 & 0,31 & 0,19 & $\mathrm{Cr}_{2} \mathrm{O}_{3}$ & 0,10 & 0,00 \\
\hline $\mathrm{FeO}$ & 3,94 & 3,89 & 3,66 & 4,56 & FeOtotal & 70,39 & 67,45 & 65,51 & 32,12 & 68,86 & 31,05 & 70,53 & 66,69 & FeOtotal & 40,90 & 39,97 \\
\hline $\mathrm{MgO}$ & 7,42 & 8,46 & 7,26 & 7,90 & MnO & 0,75 & 0,66 & 0,75 & 0,10 & 0,55 & 0,22 & 0,57 & 0,77 & $\mathrm{MnO}$ & 0,64 & 0,65 \\
\hline $\mathrm{CaO}$ & 33,45 & 34,09 & 32,66 & 33,67 & $\mathrm{MgO}$ & 4,18 & 3,90 & 6,45 & 12,35 & 2,91 & 12,68 & 3,29 & 2,12 & $\mathrm{MgO}$ & 5,74 & 5,96 \\
\hline $\mathrm{Na}_{2} \mathrm{O}$ & 3,86 & 3,19 & 4,06 & 3,45 & Zno & 0,03 & 0,11 & 0,11 & 0,23 & 0,03 & 0,07 & 0,08 & 0,14 & NiO & 0,03 & 0,05 \\
\hline $\mathrm{BaO}$ & 0,34 & 0,05 & 0,45 & 0,11 & Total & 95,68 & 95,42 & 94,73 & 98,11 & 96,58 & 97,55 & 94,60 & 96,22 & Total & 97,80 & 95,54 \\
\hline Sro & 1,13 & 0,53 & 1,24 & 0,76 & $\mathrm{FeO}$ & 41,55 & 39,66 & 17,31 & 19,42 & 47,44 & 18,49 & 41,45 & 49,49 & $\mathrm{FeO}$ & 34,42 & 32,55 \\
\hline $\mathrm{K}_{2} \mathrm{O}$ & 0,11 & 0,12 & 0,12 & 0,17 & $\mathrm{Fe}_{2} \mathrm{O}_{3}$ & 32,05 & 30,88 & 53,55 & 14,11 & 23,80 & 13,95 & 32,31 & 19,11 & $\mathrm{Fe}_{2} \mathrm{O}_{3}$ & 7,19 & 8,24 \\
\hline Total & 100,27 & 99,23 & 99,57 & 100,43 & TOTAL1 & 98,88 & 98,51 & 100,09 & 99,52 & 98,96 & 98,94 & 97,83 & 98,13 & TOTAL1 & 98,52 & 96,37 \\
\hline
\end{tabular}

mfeno $=$ microfenocristal, feno $=$ fenocristal, incl ol $=$ inclusão em olivina, bd ol = borda de fenocristal de olivina 


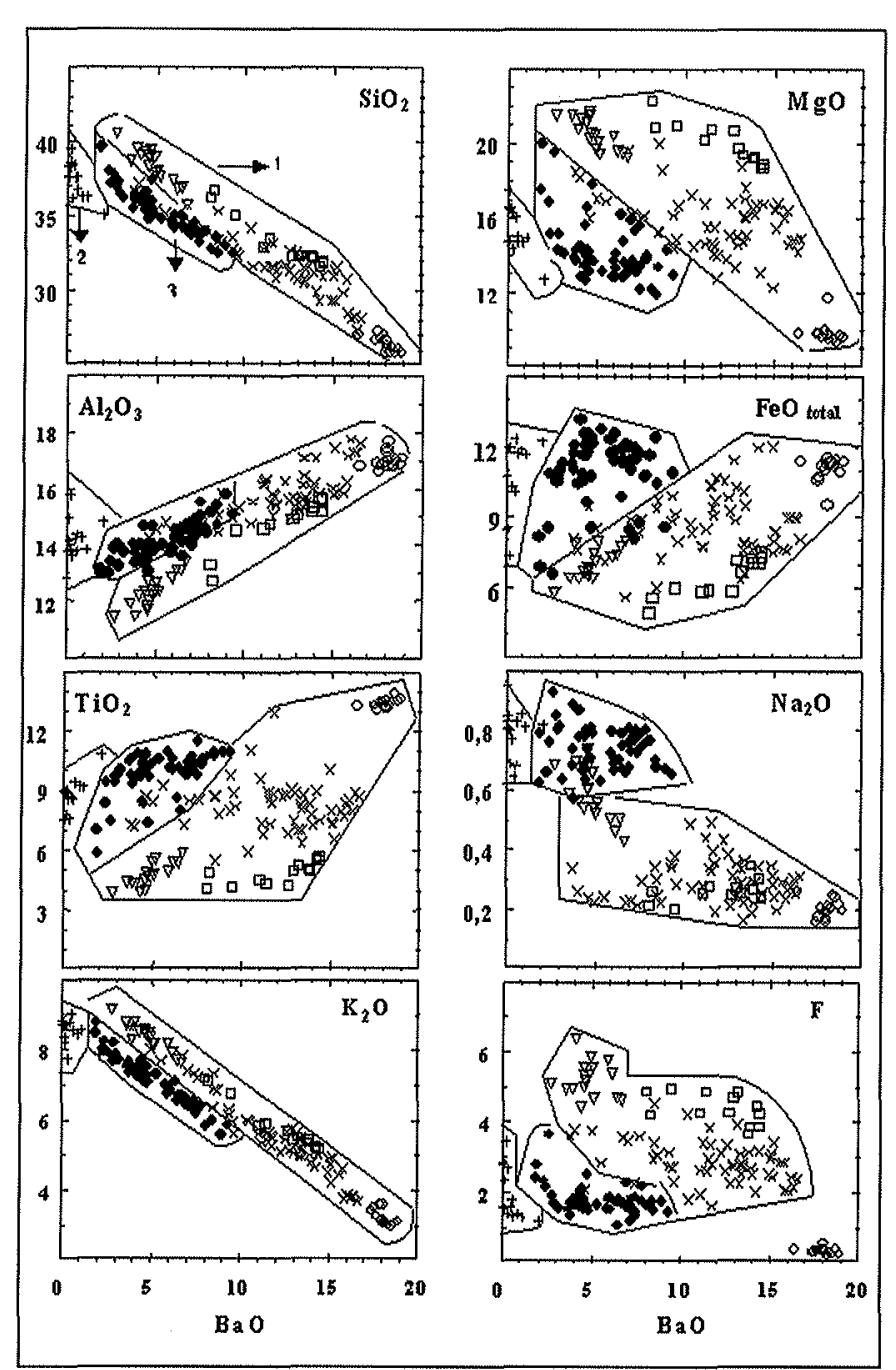

Figura 6 - Diagramas de variação de óxidos versus $\mathrm{BaO}(\%$ em peso) das biotitas (O) e flogopitas dos OLM (área 1), MEM (área 1), PIM (área 2) e BAS (área 3). Simbologia: $O L M=\mathrm{O}$ (am. 97FN58a), $\nabla$ (am. 97FN32b) e X (demais amostras); $M E M=\square ; P I M=\bullet e B A S=+$ empobrecimento em $\mathrm{MgO}$ (exceto nos basanitos de São José e Cuscuz), $\mathrm{TiO}_{2}, \mathrm{Fe}_{2} \mathrm{O}_{3 \text { total }}, \mathrm{CaO}, \mathrm{MnO}, \mathrm{Cs}, \mathrm{Y}$ e REE, e ao acréscimo em $\mathrm{Al}_{2} \mathrm{O}_{3}$ e $\mathrm{SiO}_{2}$. O Na $\mathrm{O}$ não varia e o $\mathrm{K}_{2} \mathrm{O}$ só aparece em maior quantidade nos MEM (até 2,1\%) e em um dos OLM (am. 97FN58a). O flúor varia muito nos OLM, decrescendo significativamente nos basanitos. (Fig. 9 e Fig.10)

$\mathrm{O}$ teor de alguns elementos incompatíveis como o $\mathrm{Ba}, \mathrm{Ta}$, $\mathrm{Nb}$ e Th varia dentro de um mesmo tipo litológico (Fig. 11). Os BAS podem ser divididos em dois grupos, um deles mais pobre em Th, $\mathrm{La}, \mathrm{Ba}, \mathrm{Nb}, \mathrm{Ce}$ e $\mathrm{Pb}$, caracterizado pelas rochas do corpo basanítico da Baía do Sancho e das ilhas São José e Cuscuz e, o outro, mais rico nestes elementos, representando por duas amostras da seqüência de derrames intercalados entre rochas melanefeliníticas e piroclásticas. Uma amostra em particular, o MEM da am. 97FN31, destaca-se das demais pelo seu alto conteúdo em Th, La e Ce (Fig. 11).

\section{COMPOSIÇÃO QUÍMICA DOS MINERAIS E A GÊNE-} SE DAS ROCHAS Em geral as razões $\mathrm{Mg} / \mathrm{Fe}$ das olivinas são equiparáveis as dos diopsídios com $\mathrm{Fe}^{2+} \mathrm{e} \mathrm{Fe}^{3+}$ em cada um dos tipos litológicos, indicando que ambos minerais cristalizaram em equilíbrio. $\mathrm{O}$ aumento de Ca nas olivinas mais ricas em $\mathrm{Fe}$ da matriz dos melanefelinitos e basanitos pode ser resultado do decréscimo da pressão durante a ascensão do magma (Stormer 1973). Por outro lado, a composição desse mineral, nos basanitos das Ilhas São José e Cuscuz, indica que essas rochas são mais diferenciadas que os demais basanitos ou aponta para características distintas do magma parental ou das condições de geração dessas rochas..

Nos MEM, as diferenças na quantidade e na composição química das melilitas guardam estreita relação com o teor de olivina e com a composição química total dos vários derrames. Nas rochas mais ricas em olivina, a melilita é mais pobres em $\mathrm{MgO}$ e mais ricas em $\mathrm{Al}_{2} \mathrm{O}_{3}$. Observações semelhantes, em melanefelinitos portadores de melilita, foram feitas por Melluso et al. (1996). $\mathrm{O} \mathrm{Na} 2 \mathrm{O}$ e as pequenas quantidades de $\mathrm{Ba}$ e $\mathrm{Sr}$ são incorporados no mineral substituindo o $\mathrm{Ca}$, enquanto o $\mathrm{Mg}$ é substituído por $\mathrm{Fe}\left(\mathrm{Fe}^{2+}+\mathrm{Fe}^{3+}\right)$. O Al entra nos sítios catiônicos do arcabouço tetraédrico da melilita.

As condições necessárias para a geração de magmas melilitíticos foram discutidas em trabalhos experimentais como os

Tabela 4 - Análises químicas representativas de mica dos melanefelinitos e basanitos.

\begin{tabular}{|c|c|c|c|c|c|c|c|c|c|c|c|c|c|c|c|}
\hline Mineral & & & & & & & & ica & & & & & & & \\
\hline Rocha & MEM & MEM & MEM & OLM & OLM & OLM & OLM & OLM & PIM & PIM & PIM & PIM & PIM & BAS & BAS \\
\hline $\begin{array}{l}\text { Amostra } \\
\text { Análise }\end{array}$ & $\begin{array}{r}\text { 97FN31 } \\
\text { matriz }\end{array}$ & $\begin{array}{r}99 \mathrm{FN} 56 \mathrm{~b} \\
\text { mfeno }\end{array}$ & $\begin{array}{r}99 F N 56 b \\
\text { matriz }\end{array}$ & $\begin{array}{r}97 F N 20 \\
\text { nc }\end{array}$ & $\begin{array}{r}97 F N 20 \\
\text { bd }\end{array}$ & $\begin{array}{r}97 \mathrm{FN} 32 \mathrm{~b} \\
\text { matriz }\end{array}$ & $\begin{array}{r}97 F N 58 a \\
\text { mfeno }\end{array}$ & $\begin{array}{l}\text { 99FN3 } \\
\text { mfeno }\end{array}$ & $\begin{array}{r}97 F N 13 d \\
n c\end{array}$ & $\begin{array}{r}97 \mathrm{FN} 13 \mathrm{~d} \\
\text { bd }\end{array}$ & $\begin{array}{r}97 F N 37 \\
\text { mfeno }\end{array}$ & $\begin{array}{r}97 F N 46 \\
\text { mfeno }\end{array}$ & $\begin{array}{r}\text { 99FN14 } \\
\text { matriz }\end{array}$ & $\begin{array}{l}\text { 99FN4 } \\
\text { matriz }\end{array}$ & $\begin{array}{l}\text { 99FN4 } \\
\text { mfeno }\end{array}$ \\
\hline $\mathrm{SiO}_{2}$ & 32,30 & 36,01 & 35,05 & 29,32 & 36,51 & 38,95 & 25,86 & 32,87 & 33,81 & 35,54 & 39,54 & 33,55 & 33,83 & 37,55 & 37,62 \\
\hline $\mathrm{TiO}_{2}$ & 5,04 & 9,77 & 4,13 & 10,04 & 7,21 & 4,69 & 13,86 & 6,83 & 9,77 & 10,21 & 7,76 & 10,95 & 3,35 & 8,62 & 9,03 \\
\hline $\mathrm{Al}_{2} \mathrm{O}_{3}$ & 15,20 & 13,70 & $\{4,53$ & 15,99 & 13,62 & 12,23 & 17,08 & 16,31 & 14,56 & 13,95 & 15,79 & 15,45 & 14,88 & 13,82 & 14,17 \\
\hline $\mathrm{Cr}_{2} \mathrm{O}_{3}$ & 0,01 & 0,00 & 0,00 & 0,01 & 0,05 & 0,00 & 0,00 & 0,00 & 0,00 & 0,01 & 0,00 & 0,07 & 0,00 & 0,00 & 0,00 \\
\hline $\begin{array}{l}\mathrm{FeO} \\
\mathrm{MnO}\end{array}$ & $\begin{array}{l}7,22 \\
0,07\end{array}$ & $\begin{array}{l}7,46 \\
0,08\end{array}$ & $\begin{array}{l}5,96 \\
0,05\end{array}$ & $\begin{array}{r}11,93 \\
0,12\end{array}$ & $\begin{array}{l}8,10 \\
0,04\end{array}$ & $\begin{array}{l}6,39 \\
0,07\end{array}$ & $\begin{array}{r}11,46 \\
0,05\end{array}$ & $\begin{array}{l}8,42 \\
0,06\end{array}$ & $\begin{array}{r}12,02 \\
0,07\end{array}$ & $\begin{array}{r}12,38 \\
0,10\end{array}$ & $\begin{array}{l}7,38 \\
0,10\end{array}$ & $\begin{array}{r}12,44 \\
0,11\end{array}$ & $\begin{array}{l}5,75 \\
0,04\end{array}$ & $\begin{array}{r}12,32 \\
0,15\end{array}$ & $\begin{array}{r}11,89 \\
0,10\end{array}$ \\
\hline $\mathrm{MgO}$ & 19,17 & 17,17 & 20,99 & 12,23 & 18,48 & 20,48 & 9,30 & 15,54 & 13,64 & 13,71 & 16,51 & 11,89 & 20,95 & 15,05 & 14,79 \\
\hline BaO & 13,77 & 5,82 & 9,46 & 14,93 & 3,78 & 4,87 & 18,48 & 11,23 & 6,84 & 4,71 & 0,21 & 8,38 & 11,44 & 0,53 & 0,10 \\
\hline $\mathrm{CaO}$ & 0,03 & 0,04 & 0,13 & 0,08 & 0,15 & 0,10 & 0,10 & 0,06 & 0,11 & 0,09 & 0,05 & 0,08 & 0,07 & 0,02 & 0,05 \\
\hline $\mathrm{Na}_{2} \mathrm{O}$ & 0,35 & 0,12 & 0,21 & 0,35 & 0,34 & 0,66 & 0,24 & 0,44 & 0,68 & 0,80 & 0,80 & 0,70 & 0,30 & 0,68 & 0,80 \\
\hline $\mathrm{K}_{2} \mathrm{O}$ & 5,36 & 7,97 & 6,74 & 4,50 & 8,65 & 8,47 & 2,98 & 5,34 & 6,69 & 7,26 & 8,19 & 5,98 & 5,92 & 9,01 & 8,69 \\
\hline $\mathbf{F}$ & 3,64 & 2,00 & 4,94 & 2,50 & 3,58 & 5,34 & 0,26 & 3,43 & 1,64 & 1,64 & 3,47 & 1,73 & 5,90 & 1,34 & 1,56 \\
\hline $\mathrm{Cl}$ & 0,02 & 0,00 & 0,00 & 0,02 & 0,02 & 0,02 & 0,00 & 0,00 & 0,04 & 0,02 & 0,02 & 0,01 & 0,00 & 0,00 & 0,00 \\
\hline Total & 102,16 & 100,14 & 102,19 & 102,01 & 100,52 & 102,28 & 99,68 & 100,52 & 99,85 & 100,40 & 99,82 & 101,35 & 102,43 & 99,10 & 98,81 \\
\hline O_F_CL & 1,54 & 0,84 & 2,08 & 1,06 & 1,51 & 2,25 & 0,11 & 1,44 & 0,70 & 0,69 & 1,47 & 0,73 & 2,48 & 0,57 & 0,66 \\
\hline Ctotal & 100,62 & 99,30 & 100,11 & 100,95 & 99,01 & 100,03 & 99,57 & 99,08 & 99,15 & 99,71 & 98,35 & 100,62 & 99,95 & 98,53 & 98,15 \\
\hline
\end{tabular}




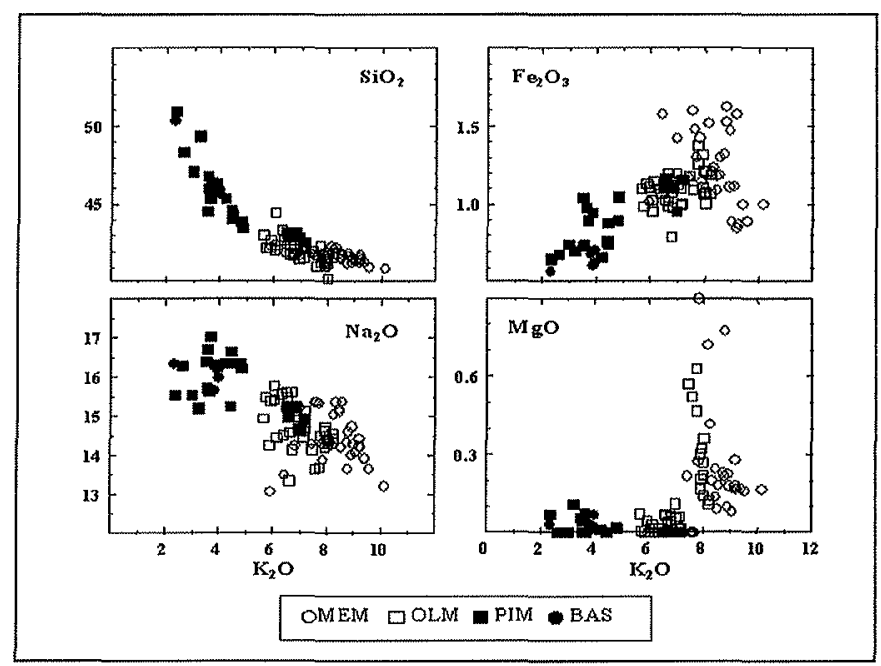

Figura 7 - Variaçôes químicas das nefelinas das rochas da Formação Quixaba. Valores expressos em \% peso. de Yoder (1973), Brey \& Green (1975 e 1977), Eggler (1975) e Wyllie (1978). Mysen et al. (1976) demonstraram que a cristalização de melilita em líquidos silicáticos está relacionada com a quantidade de água e de $\mathrm{CO}_{2}$ dissolvidos no líquido. Aumentando a fugacidade de $\mathrm{CO}_{2}$ no líquido ocorre a geração de melilita, ao passo que diminuindo a presença de $\mathrm{CO}_{2}$ há incremento na razão de $\mathrm{H}_{2} \mathrm{O} /\left(\mathrm{CO}_{2}+\mathrm{H}_{2} \mathrm{O}\right)$ e, conseqüentemente, aumenta a cristalização de olivina. A elevada $\mathrm{f}\left(\mathrm{CO}_{2}\right)$ nos magmas melilitíticos pode ser explicada pelo alto conteúdo de carbonato e $\mathrm{CO}_{2}$ da fonte e a subseqüente dissolução de $\mathrm{CO}_{2}$ no líquido silicático (Dunworth \& Wilson 1998).

As diferenças observadas nas composições químicas das nefelinas, mais ricas em $\mathrm{K}_{2} \mathrm{O}$ nos MEM e OLM do que nos PIM, também parecem estar relacionadas com a química das rochas. A pobreza em $\mathrm{SiO}_{2}$ e os maiores teores de $\mathrm{K}_{2} \mathrm{O}$ das nefelinas dos MEM quando comparadas com as dos melanefelinitos comuns, parecem ser uma feição característica das rochas portadoras de melilita (Velde \& Yoder 1978).

O caráter intersticial da mica, mineral acessório da matriz das rochas estudadas, revela tratar-se de um mineral tardio, for-

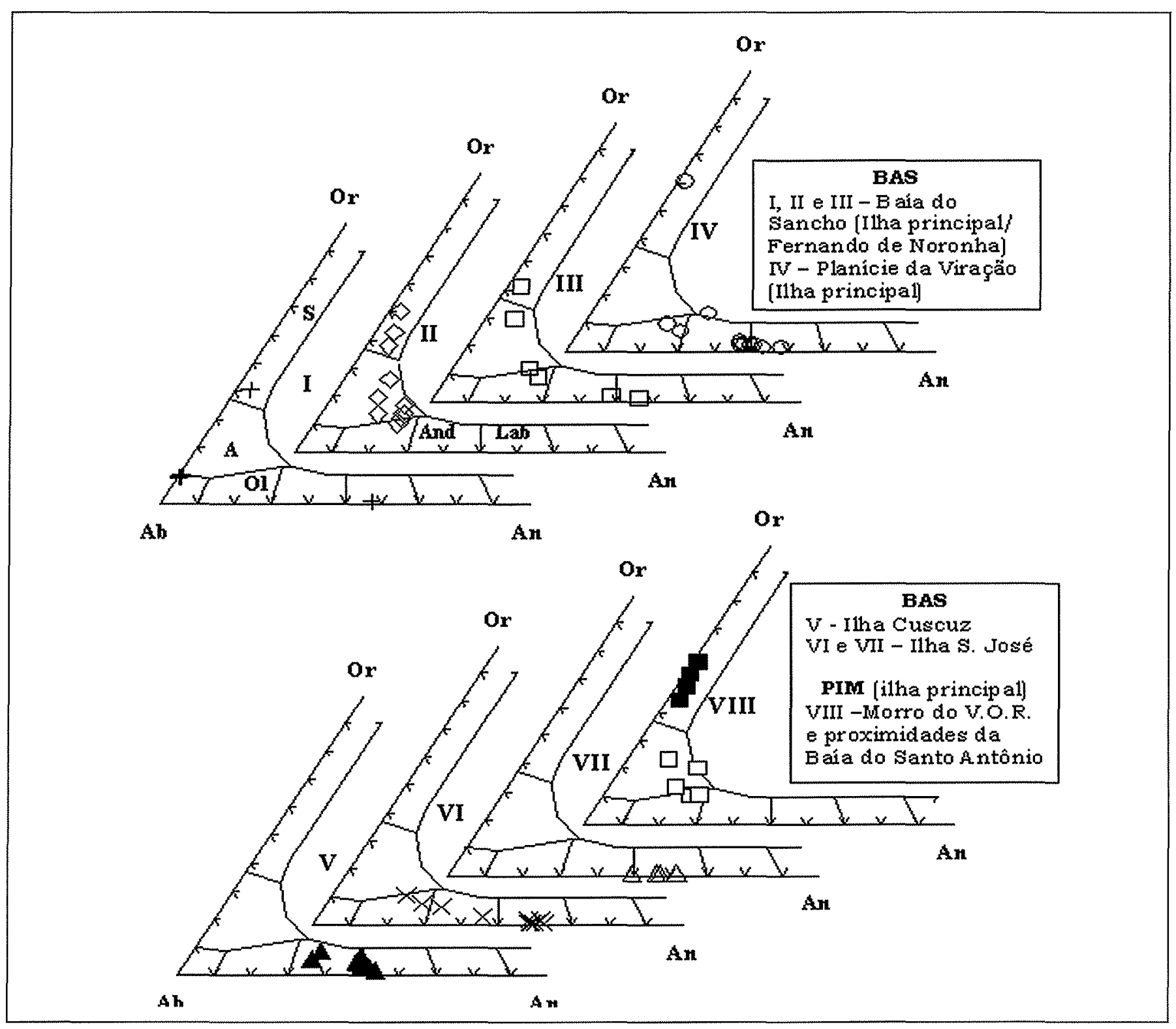

Figura 8 - Classificação e nomenclatura dos feldspatos dos PIM e BAS de Fernando de Noronha. Valores expressos em mol \%. Or - ortoclásio, Ab-albita, An-anortita, $S$-sanidina, A-anortoclásio, Ol-oligoclásio, And-andesina, Lab-labradorita. 

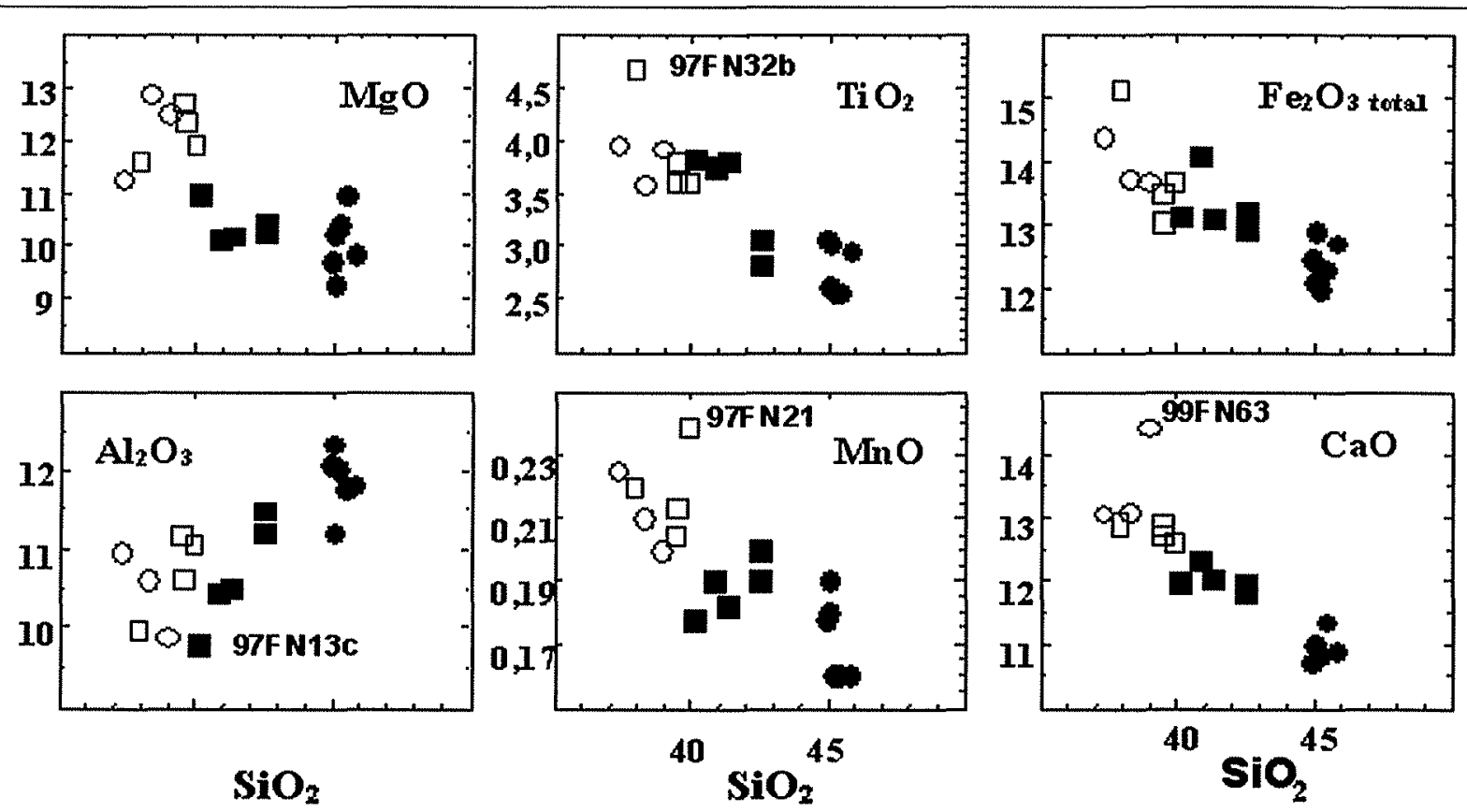

OMEM $\square$ OLM $\square$ PIM BAS

Figura 9 - Comportamento químico dos melanefelinitos e basanitos em diagramas do tipo Haker. Valores expressos em porcentagem em peso.

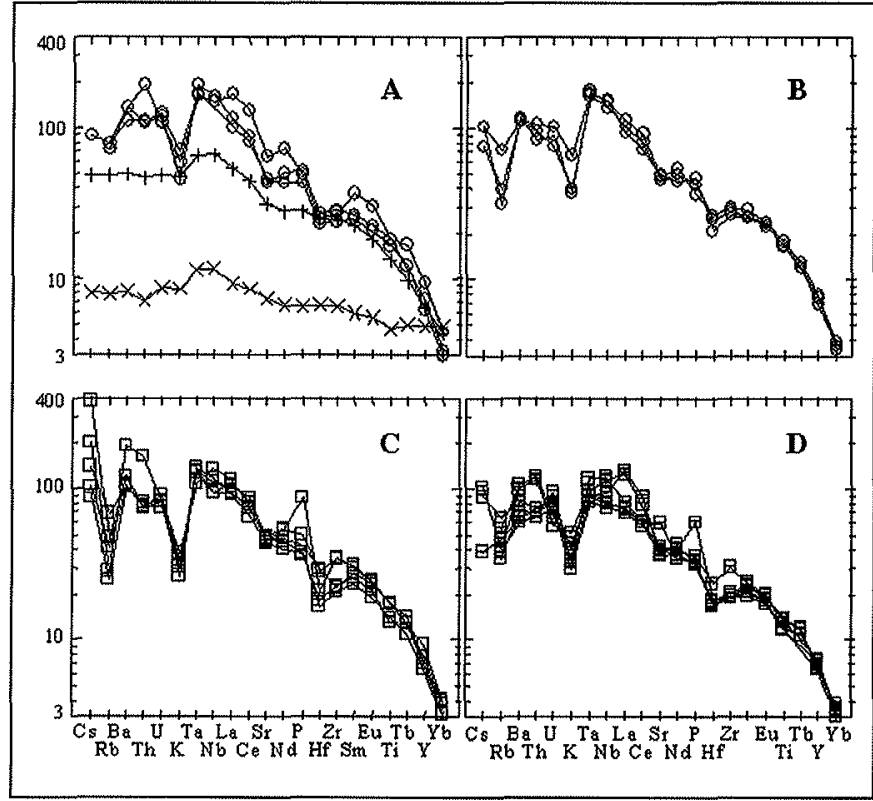

Figura 10 - Padrões de abundância dos elementos traços das rochas da Formação Quixaba normalizados segundo o manto primitivo de Sun \& McDonough (1989). $A=M E M, B=O L M$, $C=P I M$ e $D=B A S$. No diagrama $A$ foram lançados também, para fins de comparação os dados do E-MORB (x) e OIB (+) de Sun \& McDonough (1989).

mado após a cristalização das fases félsicas. Em conseqüência, a composição das flogopitas e biotitas, ricas em Ti, Ba e F, fornece informações a respeito dos líquidos finais da cristalização das lavas. $\mathrm{O}$ ingresso de $\mathrm{Ba}$ e Ti na estrutura das micas é controla-

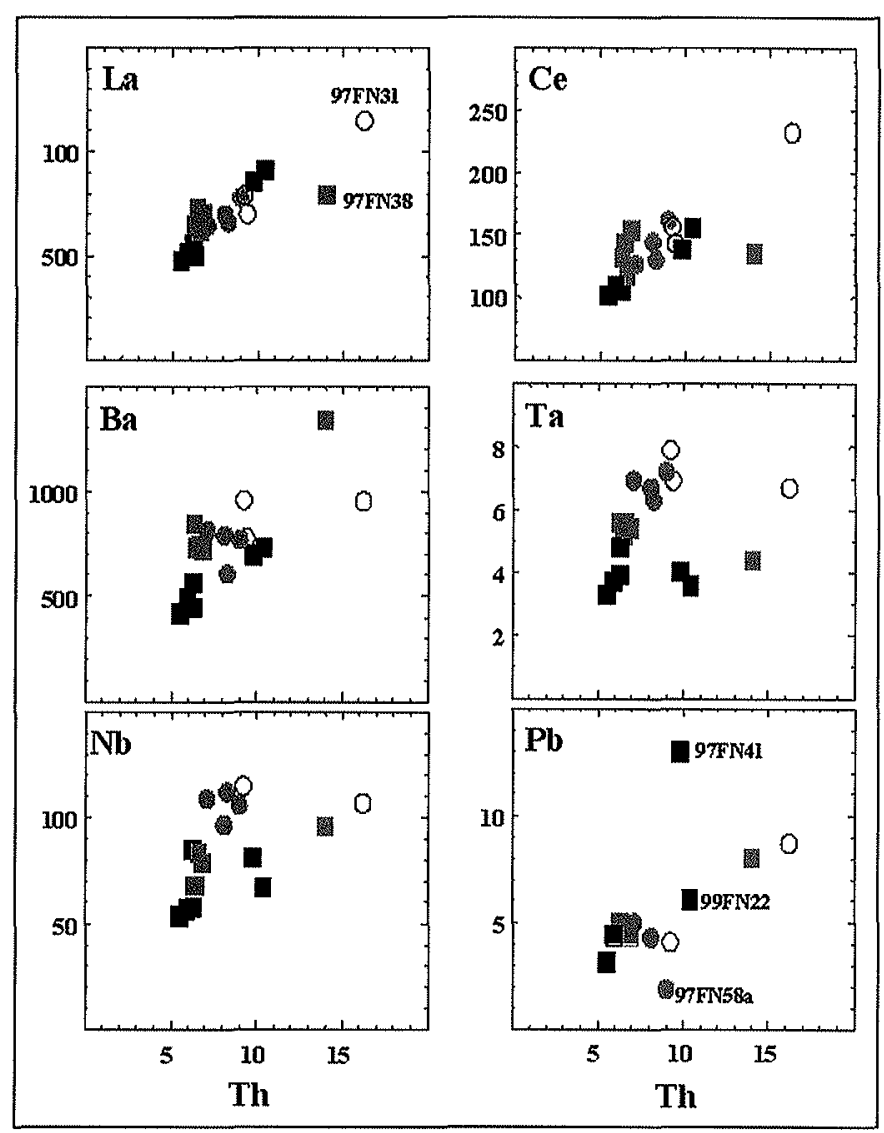

Figura 11 - Diagramas de variação de elementos terras raras leves e elementos traços em função de Th. Valores expressos em ppm. $M E M=$ circulo vazio, $O L M=$ circulo cheio cinza, $P I M=$ quadrado cheio cinza, $B A S=$ quadradro cheio preto. 
Tabela 5 - Análises químicas representativas dos melanefelinitos e basanitos da Formação Quixaba.

\begin{tabular}{|c|c|c|c|c|c|c|c|c|}
\hline Rocha & MEM & MEM & OLM & OLM & PIM & PIM & $\overline{B A S}$ & BAS \\
\hline Amostra & 97FN31 & 99 FN63 & 97FN32b & 97FN58a & 97FN45 & 97FN38 & 97FN41 & 99FN9a \\
\hline $\mathrm{SiO}_{2}$ & 37,27 & 38,92 & 37,88 & 39,48 & 41,27 & 42,51 & 44,87 & 45,42 \\
\hline $\mathrm{TiO}_{2}$ & 3,96 & 3,93 & 4,68 & 3,81 & 3,82 & 2,82 & 3,06 & 2,56 \\
\hline $\mathrm{Al}_{2} \mathrm{O}_{3}$ & 10,95 & 9,89 & 9,98 & 10,63 & 10,51 & 11,20 & 12,07 & 11,75 \\
\hline $\mathrm{Fe}_{2} \mathrm{O}_{3 \text { total }}$ & 14,39 & 13,68 & 15,12 & 13,02 & 13,10 & 12,93 & 12,45 & 12,30 \\
\hline MnO & 0,23 & 0,20 & 0,22 & 0,21 & 0,18 & 0,19 & 0,18 & 0,16 \\
\hline MgO & 11,25 & 12,51 & 11,63 & 12,35 & 10,17 & 10,27 & 9,71 & 10,95 \\
\hline $\mathrm{CaO}$ & 13,06 & 14,42 & 12,90 & 12,89 & 12,03 & 11,84 & 10,72 & 11,35 \\
\hline $\mathrm{Na}_{2} \mathrm{O}$ & 3,96 & 2,96 & 2,29 & 3,78 & 3,68 & 3,83 & 4,21 & 3,01 \\
\hline $\mathbf{K}_{2} \mathbf{O}$ & 1,79 & 1,40 & 0,89 & 1,97 & 0,91 & 1,13 & 1,54 & 0,88 \\
\hline $\mathrm{P}_{2} \mathrm{O}_{5}$ & 1,07 & 1,11 & 0,95 & 0,80 & 0,90 & 0,79 & 1,32 & 0,72 \\
\hline LOI & 1,27 & 2,16 & 2,93 & 0,04 & 2,94 & 1,65 & 0,30 & 1,28 \\
\hline Total & 99,20 & 101,18 & 99,47 & 98,98 & 99,51 & 99,16 & 100,43 & 100,38 \\
\hline $\mathbf{B a}$ & 951,00 & 956,00 & 610,23 & 773,00 & 841,70 & 1338,80 & 699,66 & 419,00 \\
\hline $\mathbf{R b}$ & 49,50 & 45,50 & 16,60 & 45,70 & 29,53 & 18,37 & 26,01 & 24,20 \\
\hline $\mathrm{sr}$ & 1368,00 & 915,60 & 1017,22 & 1008,70 & 996,52 & 972,77 & 828,92 & 880,90 \\
\hline $\mathbf{Y}$ & 43,00 & 33,00 & 30,18 & 36,00 & 32,23 & 43,46 & 29,60 & 29,00 \\
\hline $\mathbf{Z r}$ & 307,60 & 314,80 & 318,74 & 335,30 & 248,03 & 252,92 & 229,02 & 218,50 \\
\hline Nb & 107,00 & 115,00 & 112,19 & 106,00 & 67,91 & 96,28 & 80,88 & 54,00 \\
\hline Th & 16,20 & 9,20 & 8,27 & 9,00 & 6,30 & 14,02 & 9,82 & 5,50 \\
\hline $\mathbf{P b}$ & 8,70 & 4,10 & ad & 1,87 & ad & 8,33 & 12,53 & 3,20 \\
\hline $\mathbf{G a}$ & 17,80 & 17,10 & 20,39 & 15,90 & 9,94 & 19,69 & 22,26 & 16,20 \\
\hline Zn & 115,50 & 98,60 & 111,81 & 111,70 & $\mathrm{ad}$ & 120,38 & 106,62 & 106,30 \\
\hline $\mathrm{Cu}$ & 51,00 & 60,00 & 50,00 & 36,90 & ad & 46,92 & 43,41 & 51,10 \\
\hline $\mathbf{N i}$ & 183,10 & 233,90 & 205,37 & 138,00 & 51,59 & 163,73 & 140,10 & 271,40 \\
\hline $\mathbf{v}$ & 284,00 & 289,00 & 333,79 & 280,00 & 271,03 & 258,01 & 248,78 & 172,00 \\
\hline $\mathrm{Cr}$ & 247,00 & - & 330,38 & 333,00 & 252,85 & 428,79 & 282,55 & - \\
\hline Hf & 7,70 & 8,30 & 7,71 & 8,20 & 8,98 & 5,72 & 5,66 & 5,40 \\
\hline Cs & 0,70 & - & 1,01 & 0,80 & 3,00 & 1,62 & 0,83 & - \\
\hline Sc & 22,00 & - & - & 25,00 & - & - & - & - \\
\hline Ta & 6,70 & 7,90 & 6,34 & 7,20 & 5,57 & 4,37 & 3,95 & 3,30 \\
\hline Co & 45,90 & 44,70 & 63,57 & 43,80 & 14,82 & 54,25 & 49,39 & 40,10 \\
\hline $\mathbf{U}$ & 2,30 & 2,50 & 1,30 & 2,12 & 1,72 & 1,74 & 1,25 & 1,57 \\
\hline $\mathbf{w}$ & 2,90 & 1,28 & 0,52 & 1,57 & ad & 2,43 & 2,63 & 1,55 \\
\hline Sn & - & - & 2,60 & - & ad & 2,65 & 2,16 & - \\
\hline Mo & - & - & ad & - & ad & 5,08 & 7,01 & - \\
\hline La & 115,00 & 79,00 & 66,38 & 78,00 & 65,33 & 79,17 & 85,70 & 48,00 \\
\hline $\mathrm{Ce}$ & 233,00 & 157,00 & 130,95 & 162,00 & 131,64 & 134,91 & 138,62 & 101,00 \\
\hline Pr & 27,00 & 18,30 & 15,21 & 19,10 & 16,39 & 14,93 & 15,37 & 12,20 \\
\hline Nd & 99,00 & 68,00 & 66,33 & 73,00 & 64,03 & 61,53 & 54,81 & 47,00 \\
\hline $\mathrm{Sm}$ & 16,40 & 11,80 & 12,59 & 12,70 & 12,13 & 11,63 & 10,16 & 8,70 \\
\hline Eu & 5,09 & 3,70 & 3,84 & 4,00 & 3,95 & 3,58 & 3,32 & 2,90 \\
\hline Gd & 13,20 & 10,20 & 10,25 & 11,10 & 10,77 & 9,77 & 9,13 & 8,00 \\
\hline Tb & 1,80 & - & 1,40 & 1,40 & 1,42 & 1,39 & 1,26 & - \\
\hline Dy & 8,50 & 6,00 & 6,60 & 6,90 & 6,92 & 6,75 & 6,27 & 5,30 \\
\hline Ho & 1,45 & 1,09 & 1,05 & 1,22 & 1,16 & 1,20 & 1,08 & 1,00 \\
\hline Er & 3,20 & 2,40 & 2,56 & 2,60 & 2,77 & 3,08 & 2,71 & 2,20 \\
\hline $\mathrm{Tm}$ & 0,42 & - & 0,30 & 0,33 & 0,32 & 0,39 & 0,32 & - \\
\hline $\mathbf{Y b}$ & 2,20 & 1,61 & 1,61 & 1,70 & 1,74 & 2,01 & 1,92 & 1,53 \\
\hline Lu & 0,27 & 0,18 & 0,17 & 0,25 & 0,23 & 0,22 & 0,24 & 0,17 \\
\hline $\mathbf{F}$ & 1798 & - & 1988 & 1198 & 1642 & - & 1104 & - \\
\hline $\mathrm{Na}+\mathrm{K} / \mathrm{Al}$ & 0,76 & 0,64 & 0,46 & 0,79 & 0,63 & 0,64 & 0,69 & 0,48 \\
\hline
\end{tabular}

do pela concentração destes elementos nos líquidos silicáticos (Guo \& Green 1990). As variações no teor de Ba dos cristais de mica pertencentes a uma mesma amostra (por exemplo OLM, 97FN20 e PIM 97FN8) devem responder as variações de composição do líquido intersticial. Em geral, os teores de Ba são menores nos basanitos do que nos vários melanefelinitos devido ao fato de que nos primeiros, além do empobrecimento em $\mathrm{Ba}, \mathrm{o}$ elemento é incorporado preferencialmente nos feldspatos.

As micas dos BAS e dos PIM apresentam teores de $\mathrm{Na}_{2} \mathrm{O}$ mais elevados do que os dos outros melanefelinitos, em geral 
condizentes com os teores de $\mathrm{Na}_{2} \mathrm{O}$ das rochas e, principalmente, com as razões $\mathrm{Na}_{2} \mathrm{O} / \mathrm{K}_{2} \mathrm{O}$ nelas encontradas. Todos os melanefelinitos possuem quantidades semelhantes de álcalis, mas razões $\mathrm{Na}_{2} \mathrm{O} / \mathrm{K}_{2} \mathrm{O}$ distintas: \pm 2 nos MEM, 1,8 - 3 nos OLM e 3,5 - 5 nos PIM.

A substituição de $\mathrm{OH}^{-}$por $\mathrm{F}^{*}$ pode ser influenciada por vários fatores (atividade da $\mathrm{H}_{2} \mathrm{O}$, T e P). Nos experimentos de Edgar \& Arima (1985) os teores de F nas flogopitas aumentam com o decréscimo da temperatura e da quantidade de água. Foley (1990) considera que o conteúdo de $\mathrm{F}$ das micas é fortemente controlado pela atividade da $\mathrm{H}_{2} \mathrm{O}$. Em estudos experimentais este autor observou que os teores de $\mathrm{Ba}$ e $\mathrm{Al}$ das micas aumentam e os de $\mathrm{Si}, \mathrm{K}$ e $\mathrm{F}$ diminuem com o aumento da atividade da água e da $\mathrm{fO}_{2}$. A aplicação destes estudos às micas apresentadas neste trabalho sugere que, mais que mudanças na temperatura de cristalização, foram os teores de $\mathrm{H}_{2} \mathrm{O}$ que controlaram o ingresso de $\mathrm{F}$ e outros elementos nas flogopitas, sempre considerando as diferenças de composição dos líquidos residuais. Neste sentido, deve-se ressaltar que as micas mais ricas em $\mathrm{F}$ normalmente estão relacionadas com as rochas que contem melilita.

As biotitas e flogopitas das rochas do episódio Quixaba, quando comparadas com as micas de outras ocorrências alcalinas, destacam-se por ocupar um amplo campo composicional. Deve-se ressaltar, em particular, a biotita de uma das amostras que possui composição quase idêntica à das micas estudadas por Mansker et al. (1979), as quais são citadas comumente na literatura como exemplo dos maiores teores de $\mathrm{TiO}_{2}$ e $\mathrm{BaO}$ em micas de rochas magmáticas. Os estudos realizados mostram que as extensas variações composicionais das micas das rochas da Formação Quixaba podem ser explicadas por diferentes razões entre os tipos de substituições propostos na literatura (Dymek 1983, Zang et al. 1993, entre outros). O esquema geral aqui considerado é semelhante ao proposto por Mansker et al. (1979), para as micas dos nefelinitos de Havaí:

${ }^{\mathrm{XII}} \mathrm{K}+3^{\mathrm{IV}} \mathrm{Si}+3^{\mathrm{VI}}\left(\mathrm{Mg}, \mathrm{Fe}^{2+}\right)+2(\mathrm{OH}, \mathrm{F}) \rightarrow \mathrm{XII}^{\mathrm{Ba}}+\mathrm{Vl}^{\mathrm{VI}} \mathrm{C}+2$ ${ }^{\mathrm{VI}} \mathrm{Ti}+3^{\mathrm{IV}}\left(\mathrm{Al}+\mathrm{Fe}^{3+}\right)+2 \mathrm{O}^{2}+\mathrm{H}_{2}$

\section{CONSIDERAÇÕES SOBRE A EVOLUÇÃO DAS RO-}

CHAS Algumas feições das rochas melanefeliníticas e basaníticas apontam para a atuação de processos de cristalização fracionada (comportamento dos minerais e teor de elementos maiores), enquanto que outras indicam diferentes origens para estas rochas (elementos traços mais incompatíveis).

Os valores de $\mathrm{mg \#}$ em torno de 50 , e o teor de $\mathrm{Ni}=146$ -234 ppm dos melanefelinitos são inferiores aos valores mínimos considerados por Frey et al.(1978), i.e., mg\#> $68 \mathrm{e} \mathrm{Ni}>$ 320 ppm como indicativos de magmas primários. Entretanto, no caso de um simples processo de diferenciação magmática, tanto os MEM quanto os OLM podem estar representando composições próximas do líquido parental, do qual derivariam rochas mais diferenciadas. Por outro lado, os OLM e MEM são muito enriquecidos em elementos incompatíveis, com concentrações maiores que as dos PIM e dos BAS, particularmente a amostra 97FN31 (Fig. 11). As razões entre elementos traços mostram também diferenças significativas: MEM e OLM: $\mathrm{La} / \mathrm{Nb}=0,6-$ $0,7, \mathrm{Zr} / \mathrm{Nb}=2,7-3,2 ;$ PIM: $\mathrm{La} / \mathrm{Nb}=0,7-1,0 ; \mathrm{Zr} / \mathrm{Nb}=2,6-5,7$ (Ulbrich et al. 2004).

Os basanitos da Baía do Sancho são mais ricos em vários elementos traços ( $\mathrm{Zr}, \mathrm{Nb}$, Ta e $\mathrm{Hf}$ ) quando comparados com os das ilhas São José e Cuscuz e com os que ocorrem intercalados na seqüência de derrames. Os últimos, como já mencionado em item anterior, possuem maiores teores de $\mathrm{La}, \mathrm{Ce}, \mathrm{Ba}, \mathrm{Th}$ e $\mathrm{Pb}$ (Fig. 11). Razões entre elementos fortemente incompatíveis indicam que apesar das diferenças na composição dos minerais, os basanitos da Baía do Sancho e os de São José e Cuscuz possuem teores similares de $\mathrm{La} / \mathrm{Ta}=13 \pm 1 ; \mathrm{Zr} / \mathrm{Nb}=3.9 \pm 0,1 \mathrm{e} \mathrm{La} / \mathrm{Nb}=$ $0,8 \pm 0,2$, já os que compõem a seqüência de derrames apresentam valores diferentes: $\mathrm{La} / \mathrm{Ta}=23 \pm 3 ; \mathrm{Zr} / \mathrm{Nb}=3,0 \pm 0,3 ; \mathrm{La} / \mathrm{Nb}$ $=1,2 \pm 0,2$ (Ulbrich et al. 2004).

Os padrões de terras raras dos melanefelinitos mostram tendência linear e anomalias negativas de $\mathrm{Rb}$ e $\mathrm{K}$ indicando a existência de granada na fonte e retenção de flogopita no manto metassomatizado (Lopes, 2002). No trabalho de Ulbrich et al. (2004) menciona-se também que os dados isotópicos das rochas $\left({ }^{87} \mathrm{Sr} /{ }^{86} \mathrm{Sr}_{\mathrm{i}} \sim 0,7041 \mathrm{e}{ }^{143} \mathrm{Nd} /{ }^{144} \mathrm{Nd} \sim 0,51283\right)$ indicam que, além do manto empobrecido, há participação do componente mantélico EMI, cuja origem é normalmente interpretada como sendo fragmentos do manto litosférico subcontinental, desmembrados durante a ruptura dos continentes e posteriormente remobilizados em processos de fusão, dando origem ao magmatismo das ilhas vulcânicas.

Em conseqüência estima-se que há evidências da atuação de processos de cristalização fracionada, por exemplo entre os PIM e os BAS que formam níveis relativamente estreitos na seqüência de derrames. Entretanto, o elevado teor de elementos incompatíveis dos melanefelinitos e as diferenças entre as razões desses elementos nos vários tipos litológicos apontam para uma origem a partir de magmas parentais distintos, originados em fontes mantélicas distintas, ou para diferentes graus de fusão da mesma fonte.

Agradecimentos As autoras agradecem à FAPESP (Processo 97/11497-9) pelo apoio financeiro para realização dos trabalhos de campo e de laboratório, à FAB (Força Aérea Brasileira) pelo transporte de amostras e ao IBAMA pelas facilidades oferecidas para efetuar os estudos em Fernando de Noronha. Agradecemos também aos pesquisadores Dr. Horstpeter Ulbrich e Msc. Eder Luiz Santo pela colaboração nos trabalhos de campo, ao Dr. Umberto G. Cordani pela cessão de amostras da Ilha Rata e ao Dr. Eldemar de Albuquerque Menor pela obtenção de uma amostra da Ilha Dois Irmãos.

\section{Referências}

Alibert C., Michard A., Albarède F. 1983. The transition from alkali basalts to kimberlites: isotope and trace element evidence from melilitites. Contrib. Mineral. Petrol., 82: 176-186.

Almeida F, F. M. 1955. Geologia e petrologia do Arquipélago de Fernando de Noronha. DNPM, Divisão de Geol. Mineral., Monografia $13,181 \mathrm{p}$.

Almeida F.F.M. 1983. Relações tectônicas das rochas alcalinas da região meridional da plataforma sul-americana. Rev. Bras. Geoc., 13:

\section{9-158.}

Almeida F.F.M., Carneiro C.D.R., Machado Jr, D.L., Dehira, L.R. 1988. Magmatismo pós-Paleozóico no nordeste oriental do Brasil. Rev. Bras. Geoc., 18: 451-462.

Brey G. 1978. Origin of olivine melilitites - chemical and experimental constraints. J. Volcanol. Geotherm. Res., 3: 61-88.

Brey G. \& Green D.H. 1975. The role of $\mathrm{CO}_{2}$ in the genesis of olivine 
melilitite. Contrib. Mineral. Petrol., 49: 93-103.

Brey G. \& Green D.H. 1977. Systematic study of liquidus phase relations in olivine melilitite $+\mathrm{H}_{2} \mathrm{O}+\mathrm{CO}_{2}$ at high pressures and petrogenesis of an olivine melilitite magma. Contrib. Mineral. Petrol., 61: 141-162.

Cordani U. G. 1970. Idade do Vulcanismo no Oceano Atlântico Sul. Bol. IGA, 1: 9-75.

Cordani U. G.; Ulbrich M. N. C.; Onoe A. T.; Vinasco C. J. 2003. Novas determinações de idade pelos métodos $\mathrm{K}$-Ar e Ar-Ar para o Arquipélago de Fernando de Noronha. In: Congresso de Geoquímica dos Países de Língua Portuguesa, 7, Maputo, Moçambique. Revista da Fac. De Ciências, Edição Especial, 1: 167-178.

Dunworth E. A. \& Wilson M. 1998. Olivine melilitites of the SW German Tertiary Volcanic Province: mineralogy and petrogenesis. $J$. Petrol., 39 (10): 1805-1836.

Dymek R.F. 1983 Titanium, aluminium and interlayer cation substitutions in biotite from high-grade gneisses West Greenland, Germany. Amer. Mineral., 68: 880-899.

Edgar A. D. 1992. Barium-rich phlogopite and biotite from some Quaternary alkali mafic lavas, West Eifel, Germany. Eur. J. Mineral., 4: 321-330.

Edgar A.D. \& Arima M. 1985. Fluorine and chlorine contents of phlogopites crystallized from ultrapotassic rock compositions in high pressure experiments: implication for halogen reservoirs in source regions. Amer. Mineral., 70: 529-536.

Eggler D. H. 1975. Peridotite-carbonate relations in the system CaO$\mathrm{MgO}-\mathrm{SiO}_{2}-\mathrm{CO}_{2}$. Annu. Rep. Dir. Gephys. Lab., 74: 468-474.

Fodor R.V., Mukasa S.B., Sial A.N. 1998. Isotopic and trace-element indications of lithospheric and asthenospheric in Tertiary alkalic basalts, northeastern Brazil. Lithos, 43: 197-217.

Foley S.F. 1990. Experimental constraints on phlogopite chemistry in lamproites: 2. Effect of pressure-temperature variations. Eur. J. Mineral., 2: 327-341.

Frey F.A., Green D.H., Roy S.D. 1978. Integrated models of basalt petrogenesis: a study of quartz tholeiites to olivine melilitites from south eastern Australia utilizing geochemical and experimental petrological data. J. Petrol.; 19(3): 463-513.

Guo J. \& Green T.H. 1990. Experimental study of barium partitioning between phlogopite and silicate liquid at upper mantle pressure and temperature. Lithos, 24: 83-95.

Hoernle K. \& Schimcke H. -U. 1993. The petrology of tholeiites through melilite nephelinites on Gran Canaria, Canary Islands: crystal fractionation, accumulation and depths of melting. J. Petrol., 34 (3): 573-597.

Kogarko L.N., Kurat G., Ntaflos T. 2001. Carbonate metasomatism of the oceanic mantle beneath Fernando de Noroña Island, Brazil. Contrib. Mineral. Petrol., 140:577-587.

Le Bas M. J. 1987. Nephelinites and carbonatites. In: Fitton, J. G.; Upton, B. G. J. (eds) Alkaline Igneous Rocks. Geol. Soc. Special Publication, 30: 253-267.

Le Bas M.J. 1989. Nephelinitic and basanitic rocks. J. Petr., 30: 1299 1312 .

Le Maître R.W. 1989. A Classification of Igneous Rocks and Glossary of Terms. Intern. Union Geol. Sciences, Oxford, Blackwell, 192p.
Lopes R.P. 2002. O vulcanismo do Arquipélago de Fernando de Noronha, PE: Química Mineral e Geoquímica. Tese de Doutoramento, Instituto de Geociências, Universidade de São Paulo, São Paulo, $168 \mathrm{p}$

Lopes R.P \& Ulbrich M.N.C. 2001. Olivina melilita melanefelinitos da Formação Quixaba, Arquipélago de Fernando de Noronha - Pe, Brasil. In: VI CONGRESSO DE GEOQUIIMICA DOS PAÍSES DE LÍNGUA PORTUGUESA, Faro, 2001. Actas, 118-121.

Mansker W.L., Ewing R.C., Keil K. 1979. Barian-titanian biotites in nephelinites from Oahu, Hawaii. Amer. Mineral., 64:156-159.

Melluso L., Morra V., Girolamo P.D. 1996. The Mt. Vulture volcanic complex (Italy): evidence for distinct parental magmas and for residual melts with melilite. Mineral. Petrol. 56: 225-250.

Moore A. E. \&, Verwoerd W. J. 1985. The olivine melilite-"kimberlite"-carbonatite suite of Namaqualand and Bushmanland, South Africa. Trans. Geol. Soc. of South Africa, 88: 281-294.

Mysen B. O., Eggler D. H., Seitz M. Gl, Holloway J. R. 1976. Carbon dioxide in silicate melts and crystals. Part I, Solubility measurements. Amer. J. Science, 276: 455-475

Rivalenti G., Mazzucchelli M., Girardi V.A.V., Vanucci R., Barbieri M.A., Zanetti A.L., Goldstein S.L. 2000. Composition and processes of the mantle lithosphere in northeastern Brazil and Fernando de Noronha: evidence from mantle xenoliths. Contr. Mineral. Petrol., 138: 308-325.

Sahama Th.G. 1976. Composition of clinopyroxene and melilite in the Nyiragongo rocks. Carnegie Inst. Wash. Yearb, 75: 585-590.

Stormer J.C. 1973. Calcium zoning in olivine and its relationship to silica activity and pressure. Geochim. et Cosmochimica Acta 37:1815-1821.

Sun S.S. \& McDonough W.F. 1989. Chemical and isotopic systematics of oceanic basalts: implications for mantle composition and processes. In: Sauders A.D. \& Norry M.F. (eds). Magmatism in the Ocean Basins. Geol. Soc. Special Publ., 42: 313-345.

Ulbrich M.N.C. 1993. Petrography of alkaline volcanic-subvolcanic rocks from the Brazilian Fernando de Noronha Archipelago, Southern Atlantic Ocean. Bol. IG-USP, Série Cient., 24: 77-94.

Ulbrich M.N.C.\& Lopes R.P. 2000. Barium- and Titanium-rich biotites and phlogopites from Fernando de Noronha Archipelago, Brazil. In: INTERNATIONAL GEOLOGICAL CONGRESS, 31, Rio de Janeiro, SBG. Abstracts volum, CD-Rom.

Ulbrich M.N.C., Maríngolo V., Ruberti E. 1994. The geochemistry of alkaline volcanic-subvolcanic rocks from the Brazilian Fernando de Noronha Archipelago, southern Atlantic Ocean. Geochim. Brasil., $8(1): 21-39$.

Ulbrich M.N.C., Marques L.S., Lopes R.P. 2004. As ilhas vulcânicas brasileiras: Fernando de Noronha e Trindade. In: Geologia do Continente Sul-Americano: evolução da obra de Fernando Flávio Marques de Almeida. Beca Produções Culturais Ltda., São Paulo, Cap. XXXI: $555-573$

Ulbrich M.N.C. \& Ruberti E. 1992. Nova ocorrência de rochas basaníticas no Arquipélago de Fernando de Noronha. In: CONGRESSO BRASILEIRO DE GEOLOGIA, 37, São Paulo, 1992. Bol. Resumos Expandidos, SBG, 2: 83-84.

Velde D. \& Yoder H. S. Jr. 1977. Melilite and melilite-bearing igneous rocks. Carnegie Inst. Wash. Yearb, 76: 478-485.

Velde D. \& Yoder H. S. Jr. 1978. Nepheline solid solutions in melili- 
te-bearing eruptive rocks and olivine nephelinites. Carnegie Inst. Wash. Yearb, 77: 761-767.

Weaver B.L. 1990. Geochemistry of highly-undersaturated ocean island basalt suites from the South Atlantic Ocean: Fernando de Noronha and Trindade islands. Contrib. Mineral. Petrol., 105: 502-515

Wyllie P. J. 1978. Peridotite- $\mathrm{CO}_{2}-\mathrm{H}_{2} \mathrm{O}$ and the low-velocity zone. Bull. Volcanol., 41 (4): 670-683.
Yoder H. S. Jr. 1973. Melilite stability and paragenesis. Fortschr: Miner., 50: 140-173.

Zhang M., Suddaby P., Thompson R.N., Dungan M.A. 1993. Barian titanian phlogopite from potassic lavas in northeast China: chemistry substitutions and paragenesis. Amer. Mineral., 78: 1056-1065.

Manuscrito A-1603

Revisão aceita em 14 de junho de 2006 